\title{
Caracterização petrográfica e litogeoquímica dos mármores e rochas calcissilicáticas do Vale do Jacurici, Bahia: condições paleoambientais e processos fosfogenéticos
}

\author{
Petrographic and litogeochemical characterization of Vale do Jacurici marbles and \\ calc-silicate rocks, Bahia: paleoenvironmental conditions and phosphogenetic processes \\ Mariana Andriotti Gama1 (D), Aroldo Misi² (D), José Haroldo da Silva Sá2 (D), \\ Luis Rodrigues dos Santos de Oliveira ${ }^{1}$ (1), Tatiana Silva Ribeiro ${ }^{1}$ (1) \\ ${ }^{1}$ Universidade Federal da Bahia - UFBA, Rua Barão de Jeremoabo, s/n, Campus Universitário de Ondina, CEP: 40170-020, \\ Salvador, BA, BR (mariana.ageo@gmail.com; rodrigues.oliveira@hotmail.com; tatiana_geologia@yahoo.com.br) \\ 2UFBA, Instituto de Geociências, Grupo de Metalogênese, Centro de Pesquisa em Geofísica e Geologia, Salvador, BA, BR \\ (misi@ufba.br; haroldo.sa@gmail.com)
}

Recebido em $1^{\circ}$ de setembro de 2019; aceito em 14 de abril de 2021.

\begin{abstract}
Resumo
Baseando-se em interpretações paleoambientais utilizando dados geoquímicos, os mármores e as rochas calcissilicáticas do Vale do Jacurici, centro-norte da Bahia, demonstraram estar associados a um paleoambiente de deposição marinho raso Paleoproterozoico. Essas rochas encontram-se deformadas, metassomatizadas e metamorfizadas em condições de anfibolito alto a granulito. São intruditas pelo Sienito de Itiúba e pelo Complexo Máfico-ultramáfico Vale do Jacurici, mineralizado em cromita, relação que sugere idade mínima paleoproterozoica para a sucessão. Os estudos realizados em testemunhos de sondagem permitiram a caracterização de mármores, diopsiditos e rochas calcissilicáticas granulitizadas. São identificadas assinaturas marinhas preservadas em padrões de elementos terras-raras (ETR $+\mathrm{Y})$, bem como anomalias negativas de Ce, positivas de Y e Gd e relações Y/Ho próximas aos valores da água do mar (60-168) nos mármores. Foram constatados padrões de contaminação crustal que indicam componentes provenientes de input terrígeno, resultando em relações positivas $\mathrm{Zr}$ versus Hf, enriquecimento relativo de metais traços, $\Sigma \mathrm{ETR}+\mathrm{Y}$ e razões $\mathrm{Pr} / \mathrm{Yb}_{[\mathrm{SN}]}$, padrões $\mathrm{Y} / \mathrm{Ho}(<30)$ e anomalias menos acentuadas, sobretudo nas rochas calcissilicáticas. A presença de magnitudes variáveis de anomalias positivas de Eu pode refletir contribuição de assinaturas das águas dos mares arqueanos residuais e influência de fluidos magmáticos tardios. A ocorrência de valores anômalos de $\mathrm{P}_{2} \mathrm{O}_{5}$ nos mármores $(1,38$ e 4,56\%) e diopsiditos $(2,07$ e $2,3 \%)$ relacionada às razões $\mathrm{Y} / \mathrm{Ho}$ (parâmetro de contaminação detrítica na bacia) sugere assinaturas de zonas limítrofes entre contribuição terrígena e marinha, bem como evidencia controle estratigráfico preservado nas concentrações de fósforo. Esses dados indicam um paleoambiente influenciado por eventos climáticos globais favoráveis à fosfogênese, envolvendo alta disponibilidade de oxigênio, cenário semelhante aos registros em bacias paleoproterozoicas mineralizadas em fosfato sedimentar, no Cráton do São Francisco (CSF) e em outras partes do mundo.
\end{abstract}

Palavras-chave: Vale do Jacurici; Mármores; Calcissilicáticas; Condições paleoambientais; Fosfogênese.

\begin{abstract}
Based on paleoenvironmental interpretations with geochemical data, Vale do Jacurici marbles and calcissilicatic rocks, North-central of Bahia State, demonstrated an association with a paleoproterozoic shallow marine paleoenvironment. These rocks are deformed, metassomatized, and metamorphosed under high amphibolite to granulite conditions. They are intruded by the Itiúba Sienite and Mafic-ultramafic Complex Vale do Jacurici, mineralized in chromite, relation that indicates the minimum Paleoproterozoic age for the succession. In marble, marine signatures are preserved in RRE $+\mathrm{Y}$ patterns (PAAS normalized) with negative Ce-anomalies, positive $\mathrm{Y}$ and $\mathrm{Gd}$-anomalies, and $\mathrm{Y} / \mathrm{Ho}$ ratios near the values of sea water (60-168). Crustal contamination patterns indicate the presence of terrigenous components, especially in calc-silicate rocks, resulting in positive relations $\mathrm{Zr}$ versus $\mathrm{Hf}$, relative enrichment of trace metals, $\Sigma \mathrm{RRE}+\mathrm{Y}$ and $\mathrm{Pr} / \mathrm{Yb}{ }_{[\mathrm{SN}]}, \mathrm{Y} / \mathrm{Ho}(<30)$, and less marked anomalies. The presence of variable magnitudes of positive Eu-anomalies may reflect the contribution of signatures from residual Archaean seas and the influence of late magmatic fluids. The occourrence of anomalous values
\end{abstract}


of $\mathrm{P}_{2} \mathrm{O}_{5}$ in marbles (1.38 and 4.56\%) and diopsidites (2.07 and 2.3\%) delimited with $\mathrm{Y} / \mathrm{Ho}$ ratio (parameter of detritic contamination in the basin) that indicade signature of zones between terrestrial and marine contribution, evidences the stratigraphic control in phosphate concentration. These data indicate a paleoenvironment influenced by global climatic events that favors phosphogenesis, involving oxygen availability, similar scenario to Paleoproterozoic phosphate mineralized sedimentary basins in São Francisco Craton (SFC) and other parts of the world.

Keywords: Jacuricy Valley; marbles; Calc-silicate rocks; Paleoenviromental conditions; Phosphogenesis.

\section{INTRODUÇÃO}

Na região do Vale do Jacurici, localizado no município de Andorinha, centro-norte da Bahia, ocorre uma sucessão supracrustal constituída predominantemente por mármores e rochas calcissilicáticas, estruturadas como lentes descontínuas encaixadas em gnaisses de origem diversa. Esse conjunto de rochas, deformadas, metassomatizadas e metamorfizadas em condições de anfibolito alto a granulito, representa uma das principais encaixantes do corpo máfico-ultramáfico acamadado com depósitos de cromita (Del Lama et al., 2001).

As sequências sedimentares paleoproterozoicas presentes na região NE do Cráton do São Francisco (CSF), constituídas por quartzitos, rochas calcissilicáticas, diopsiditos, mármores, formações ferríferas e xistos grafitosos, são extremamente deformadas, metamorfizadas e encontram-se distribuídas em faixas segmentadas. Notadamente, as litofácies carbonáticas e calcissilicáticas apresentam implicações metalogenéticas, relacionadas principalmente com depósitos calcíticos, dolomíticos, fosfáticos e skarnitos.

As rochas fosfáticas sedimentares, ou fosforitos $\left(\mathrm{P}_{2} \mathrm{O}_{5}\right.$ $>10 \%$ ), são os mais importantes registros do ciclo do $\mathrm{P}$ ao longo do tempo geológico, compreendendo rochas sedimentares biogenéticas, formadas em ambiente marinho, sob condições complexas, muito peculiares e ainda pouco definidas, constituindo o sistema fosfogenético (Kazakov, 1937; Nelson et al., 2010; Pufahl e Hiatt, 2012). O evento fosfogenético mais antigo teria ocorrido durante o Paleoproterozoico, como consequência do Grande Evento de Oxidação da Terra (Great Oxidation Event - GOE). A ação do intemperismo químico nas rochas continentais teria favorecido o input de nutrientes, cátions e ânions aos oceanos, incluindo grande quantidade de $\mathrm{PO}_{4}^{-3}$ (Papineau, 2010; Pufahl e Hiatt, 2012).

O estudo geoquímico dessas rochas proporciona importantes informações de reconstrução de condições paleoambientais, sobretudo em cinturões orogenéticos pré-cambrianos, em que estruturas sedimentares primárias são raramente preservadas. A sua complexa associação mineralógica e, quando possível, a obtenção de assinaturas geoquímicas primordiais preservadas em elementos-traço, com destaque para os elementos terras-raras (ETR), em relação a padrões definidos e conhecidos, representam as ferramentas básicas nessa linha de pesquisa, tendo em vista que o comportamento desses elementos no ambiente sedimentar marinho é controlado principalmente pelas condições da água do mar, atmosféricas e biosféricas, as quais são peculiares e oscilantes ao longo do tempo geológico (Veizer et al., 1992; Knoll et al., 1995; Bau, 1999; Gaertner et al., 2011; Swart, 2015).

A região do Vale do Jacurici localiza-se entre o limite de dois segmentos do nordeste do CSF no estado da Bahia (Figura 1), a porção norte do Cinturão Itabuna-SalvadorCuraçá (CISC), ao oeste, e o Bloco Serrinha (BS), ao leste, havendo divergência na literatura disponível quanto a sua inserção estratigráfica e geotectônica. Apesar de o ambiente deposicional dessas rochas ser desconhecido, a idade mínima de deposição para essa sucessão atualmente é tida como $2084 \mathrm{Ma}$, idade obtida para o Sienito de Itúba, e de $2085 \pm 5 \mathrm{Ma}$, idade do Complexo Máfico-ultramáfico Vale do Jacurici, ambos intrusivos (Oliveira et al., 2004). Dados de $\delta^{13} \mathrm{C}$ variam de $+2.2 \mathrm{a}+6.9 \%$, sendo correlacionados com os valores de dolomitos depositados em bacia marinha rasa durante o Paleoproterozoico e mineralizados em fosfato (fosforito), presentes no Supergrupo Aravalli (Índia) (Maheshwari et al., 2010).

Estudos realizados por Ribeiro $(2016,2017)$ caracterizaram as rochas carbonáticas e calcissilicáticas, inseridas nos terrenos do CISC, que compõem o Complexo Tanque Novo-Ipirá, na folha Pintadas, como de possível idade paleoproterozoica. Este complexo, depositado em ambiente plataformal raso, exibe diversas ocorrências de fosfato, além de relevantes semelhanças litológicas e geoquímicas com a sucessão do Vale do Jacurici, já notadas por Gama (2014) e Silveira et al. (2015).

Este estudo contribui para a caracterização petrológica das rochas que constituem a sucessão supracrustal do Vale do Jacurici, e teve os objetivos de reconstituir as condições paleoambientais da bacia em que foi depositada, avaliar o seu potencial metalogenético para fosfato e indicar os processos que possam ter controlado acumulações de $\mathrm{P}_{2} \mathrm{O}_{5}$ por meio de correlações geoquímicas. Este conteúdo não só possibilita melhor contextualização geotectônica da unidade no CSF, como também serve de incentivo à pesquisa geológica em outras sucessões pré-cambrianas similares, cujo potencial metalogenético é pouco explorado devido a sua descontinuidade e seu alto grau deformacional e metamórfico, processos que obliteram significativamente estruturas primárias. 


\section{CONTEXTO GEOLÓGICO}

O Vale do Jacurici está localizado na porção centro-norte do CSF, que, por sua vez, representa um remanescente de crosta continental arqueana-paleoproterozoica de grande importância da Plataforma Sul-Americana (Almeida, 1967, 1977). O modelo de evolução tectônica do CSF, embasado em dados petrológicos, geocronológicos e isotópicos interpretados nas últimas décadas, evidencia a colisão dos blocos crustais arqueanos (Gavião, Serrinha, Jequié e ItabunaSalvador-Curaçá) no Paleoproterozoico, com amalgamação e metamorfismo em torno de $2.0 \mathrm{Ga}$ (Barbosa et al., 2003).

Apesar de representar um modelo conciso que elucida razoavelmente a evolução geotectônica desses terrenos, os autores Barbosa et al. (2003) destacam a complexidade de se estabelecer os limites físicos e temporais entre o Arqueano e o Paleoproterozoico nesses segmentos.

\section{Rochas do Vale do Jacurici}

As litologias constituintes da região do Vale do Jacurici estão posicionadas diretamente ao leste do Sienito de Itiúba, sendo compostas por rochas altamente deformadas, dobradas e falhadas, configuradas descontinuamente em uma megassinclinal com vergência predominante para leste, no trend $\mathrm{N}-\mathrm{S}$, ao longo de cerca de $25 \mathrm{~km}$ (Figura 1).

A sequência estratigráfica foi descrita inicialmente por Jardim de Sá (1983) e Marinho et al. (1986), elaborada
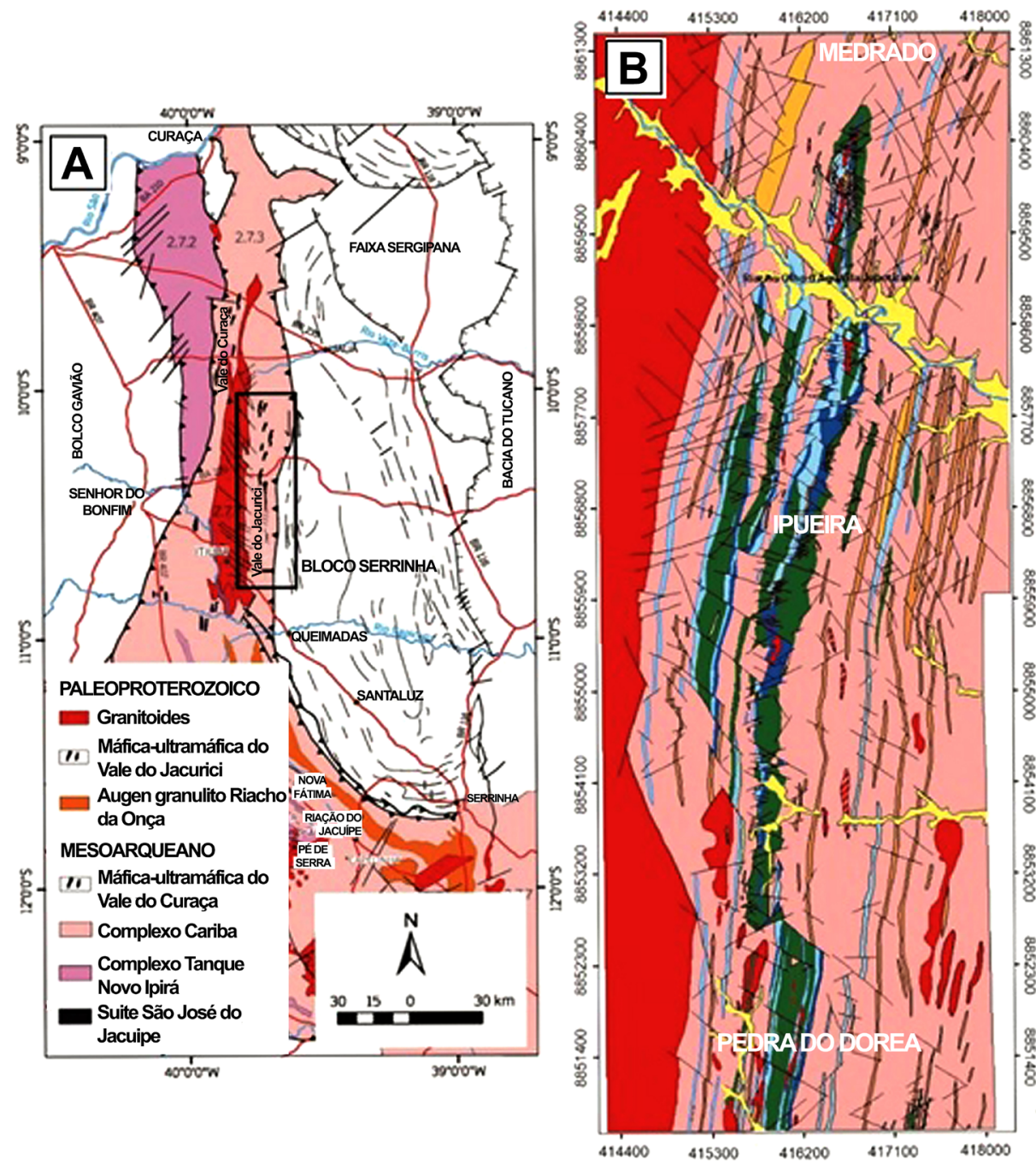

QUATERNÁRIO

Aluviões

ARQUANO E

PALEOPROTEROZOICO

$\square$ Granitoides

Ortognaisses G1

Sill máfico-ultramáfico

SEQUÊNCIA SUPRACRUSTAL

Gnaisses bandados

Mármores

Diopsiditos

Piroxênio anfibolitos

Metacherts

CONVENÇÕES

DIA Veio de quartzo

Drenagem principal

_ Falhas/fraturas

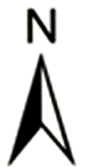

$1: 30.000$

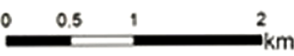

Figura 1. (A) Mapa geológico simplificado do segmento norte do Cinturão-Itabuna-Salvador-Curaçá e limites com BG e BS, com destaque para o Vale do Jacurici. Simplificado e atualizado de Barbosa e Dominguez (1996), Kosin et al. (2003) e Oliveira et al. (2010). (Modificado por Barbosa et al., 2012); (B) mapa geológico de detalhe do vale do Jacurici envolvendo os distritos de Pedra do Dórea, Ipueira e Medrado (Cia Ferro-Ligas da Bahia - FERBASA, 2014). 
utilizando-se relações estruturais e intrusivas de diferentes gerações de rochas plutônicas que ocorrem na área. A sequência sugerida apresenta, da base para o topo:

- Sequência supracrustal metamorfizada;

- Sill diferenciado máfico-ultramáfico contendo depósitos de cromita;

- Ortognaisses G1;

- Diques máficos;

- Ortognaisses G2;

- Granitoides G3;

- Rochas pegmatíticas;

- Diques de metadiabásio.

A sequência supracrustal descrita por Jardim de Sá (1983) e Marinho et al. (1986) é constituída de variados litotipos metamorfizados em fácies anfibolito alto a granulito e metassomatizados (Del Lama et al., 2001), dentre eles:

I. diopsiditos;

II. mármores;

III. quartzitos impuros e metacherte;

IV. formações ferríferas;

V. grafititos;

VI. granulitos paraderivados e calcissilicáticos.

Nesse modelo, as rochas são alocadas no Complexo Caraíba, constituinte do CISC (Figura 1). As litologias (i), (ii), (iii) e (vi) são as que ocorrem com maior frequência e, por ocorrerem diretamente associadas entre si, representam o foco do presente trabalho.

Esse conjunto de rochas é intrudido diretamente por corpos máficos-ultramáficos estratificados, de idade paleoproterozoica, mineralizados em cromo e explotados pela Companhia de Ferro Ligas da Bahia (FERBASA). Essas rochas encontram-se dispostas em um trend $\mathrm{N}-\mathrm{S}$, sendo interpretadas como constituintes de um sill de origem cumulática, posteriormente afetado por intensa deformação e metamorfismo de fácies anfibolito, variando composicionalmente de dunitos até ortopiroxenitos e gabronoritos (Marques e Ferreira Filho, 2003).

As rochas metassedimentares foram caracterizadas e classificadas posteriormente por Del Lama et al. (2001), Maheshwari et al. (2010) e Gama (2014). Dados de $\delta^{13} \mathrm{C}$, obtidos nos mármores por Maheshwari et al. (2010) variam de +2.2 a $+6.9 \%$, correlacionáveis aos valores dos dolomitos paleoproterozoicos mineralizados em fosfato (fosforito), presentes no Supergrupo Aravalli (Índia). Ainda, relações estruturais e intrusivas com o Sienito de Itiúba, de idade U-Pb em zircão de $2084 \pm$ $9 \mathrm{Ma}$, e com o Complexo Máfico-ultramáfico Vale do Jacurici, de idade $2085 \pm 5 \mathrm{Ma}$, obtidos por Oliveira et al. (2004), sugerem idade Paleoproterozoica para a sucessão estudada.

\section{MÉTODOS ANALÍTICOS}

Este trabalho foi desenvolvido por meio do estudo e da amostragem de testemunhos ao longo de 10 furos de sondagem, totalizando $2.070,75 \mathrm{~m}$, em que foram englobados os distritos minerários de Medrado, ao norte do Vale do Jacurici, de Ipueira e Pedra do Dórea, na porção sul. Estudos petrográficos foram desenvolvidos visando a determinação das fácies litológicas, bem como suas relações. Essa etapa permitiu a identificação de diversas fases minerais, bem como de cristais de apatita, os quais foram analisados por meio de microscopia eletrônica de varredura (MEV) no Laboratório Multiusuário em Microscopia Eletrônica da Universidade Federal da Bahia (LAMUME), com equipamento modelo JSM-6610LV - JEOL, e de gráficos gerados no software Aztec.

Análises por difratometria de raios X (DRX) foram realizadas para identificação de fases cristalinas, sobretudo para a diferenciação do carbonato predominante (calcita versus dolomita). A preparação foi realizada por moagem manual e mecânica. As análises foram feitas em difratômetro D2 Phaser (2nd Geração) - Bruker no Laboratório de Tecnologia Mineral - RAIOS X da Universidade Federal da Bahia (LAPAG), com a utilização do software Difract Suit EVA nas interpretações.

Um total de 51 amostras coletadas foi analisado quimicamente por intermédio de fluorescência de raios X (FRX) no laboratório da SGS-GEOSOL, para determinação dos teores de elementos maiores; espectrometria de emissão atômica por plasma acoplado indutivamente (ICP-OES), para elementos-traço, e espectrometria de massa por plasma indutivamente acoplado (ICPS-MS), para os elementos terras-raras. Os elementos terras-raras e ítrio $(\mathrm{ETR}+\mathrm{Y})$ analisados neste trabalho foram normalizados com a composição do folhelho Post Archean Australian Shale (PAAS), de McLennan (1989).

\section{OCORRÊNCIA, DISTRIBUIÇÃO E PETROGRAFIA DAS LITOFÁCIES}

A sucessão supracrustal do Vale do Jacurici é representada por um complexo conjunto de mármores e rochas calcissilicáticas intensamente deformado, fraturado, metamorfizado em alto grau e metassomatizado, o que dificulta a reconstituição do seu ambiente de formação e empilhamento estratigráfico original (Figuras 2 e 3). Por conseguinte, procurou-se analisar as porções mais representativas de cada membro, evitando-se zonas de faturamento, milonitização, metassomatismo e intrusões (Figura 3).

As porções mais calcissilicáticas apresentam, por vezes, bandamento gnáissico milimétrico a centimétrico, denominado estruturalmente de S1, paralelo ao acamadamento 
primário S0. Além disso, as rochas que compõem essa sucessão representam as encaixantes principais do corpo máfico-ultramáfico mineralizado em cromo (Figura 3).

\section{Mármores}

Os mármores exibem estrutura maciça (sem orientação preferencial), granulação fina a grossa e coloração branca a cinza, esverdeada, por vezes alaranjada, marcada pela predominância de carbonato e/ou serpentina/olivina.

Foram separados dois grupos principais, utilizando-se como base também os padrões geoquímicos. Em ambos os grupos, os carbonatos são predominantemente calcita magnesiana, com menor ocorrência de dolomita, diferenciadas somente por meio de DRX. As composições modais de carbonato, quantificadas por contagem modal em lâminas delgadas, perfazem, em média, $60 \%$ no Grupo 1 e $55 \%$ no Grupo 2. Estes ocorrem em matriz com textura granoblástica em meio a grãos maiores de forsterita, totalmente ou parcialmente substituídos pela serpentina lizardita. Serpentina ocorre como cristais inequigranulares arredondados, por vezes alongados e fibrosos, com proporção média de $30 \%$ da composição das amostras do Grupo 1 e de $23 \%$ do Grupo 2. Tem granulometria fina $(0,1<\mathrm{e} \leq 1 \mathrm{~mm})$ a média $(1<\mathrm{e}$ $\leq 5 \mathrm{~mm}$ ) sob microscópio petrográfico, no entanto, é possível observar cristais de serpentina da ordem de alguns centímetros. Observa-se valor médio modal de 1,7 a $10 \%$ de forsterita reliquial, com maior frequência no Grupo 1 .
Esses aspectos fornecem à rocha um caráter porfiroblástico, sem orientação preferencial de grãos.

Menores constituintes modais (até 8\%) são representados por biotita, muscovita, diopsídio, apatita, granada, magnetita e quartzo, variação mineralógica típica de mármores impuros em alto grau metamórfico. Biotita, muscovita e granada são observadas com maior frequência nas amostras do Grupo 2. A apatita ocorre como cristais euédricos a subédricos, de granulometria centimétrica. Em microscópio petrográfico, os cristais de apatita são incolores e ocorrem associados à matriz carbonática (Figura 4). Análises de DRX nos mármores com maior teor de $\mathrm{P}_{2} \mathrm{O}_{5}$ indicam a presença de fluorapatita.

Puderam ser classificados como: serpentina (lizardita) mármores; serpentina (lizardita)-olivina (forsterita) mármores com e sem granada e/ou magnetita; serpentina (lizardita)-apatita mármores; serpentina (lizardita)-olivina (forsterita)-biotita mármores; e mármores puros.

\section{Diopsiditos}

Na sucessão, ocorrem diopsiditos frequentemente intercalados com os serpentina mármores e as rochas calcissilicáticas granulitizadas, apresentando zonas de composição gradual entre essas litologias (Figuras 2 e 3). Fora da zona de intercalação, os diopsiditos apresentam granulação variada e estrutura maciça, cor cinza-clara, cinza esverdeada e verde-clara, ocorrendo ao longo de dezenas de metros. Nas zonas de intercalação,
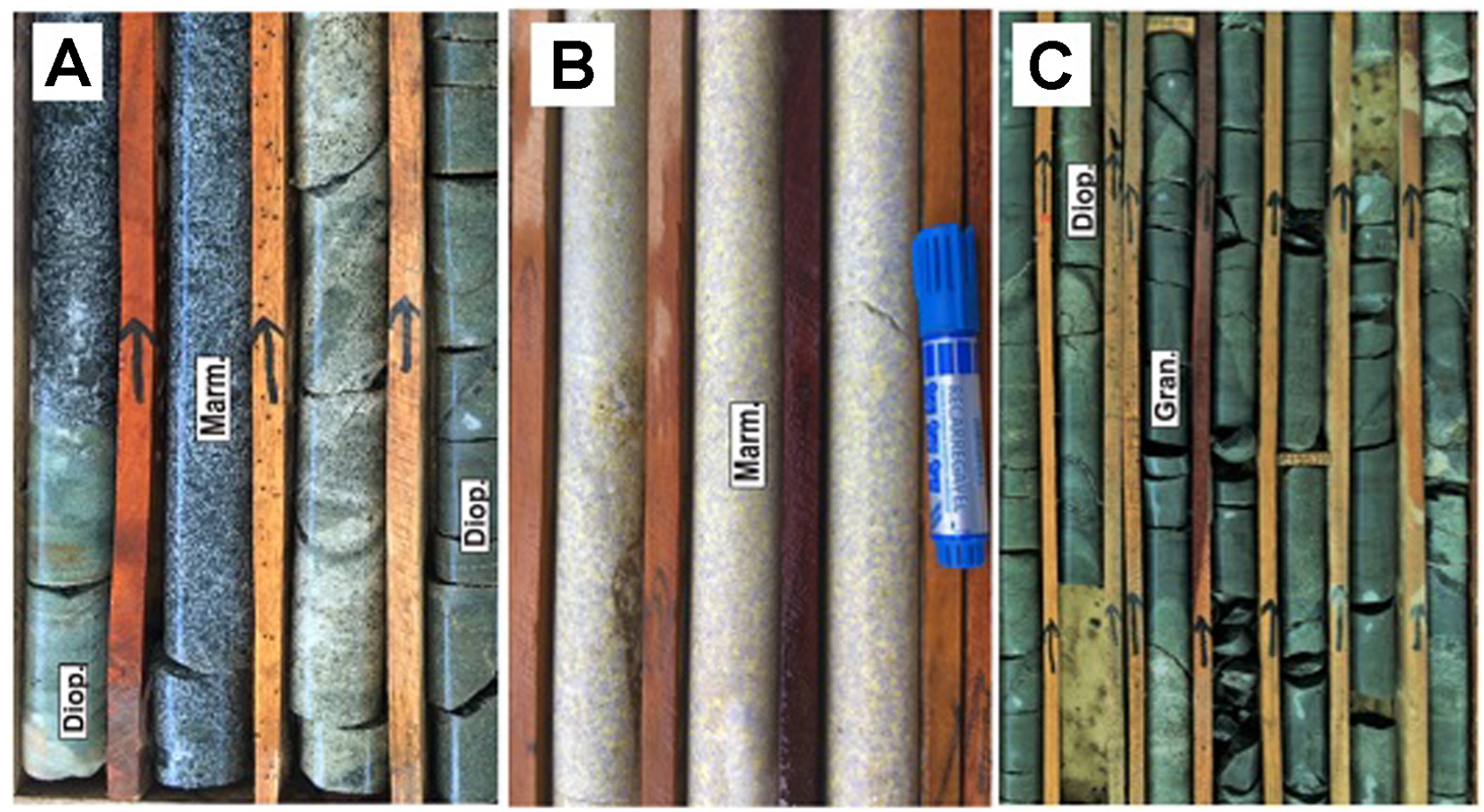

Figura 2. Ilustração representativa dos principais litotipos estudados em testemunhos de sondagem. (A) Diopsiditos intercalados com mármores; (B) serpentina mármores maciços; (C) diopsiditos e rochas calcissilicáticas granulitizadas e intercaladas. 


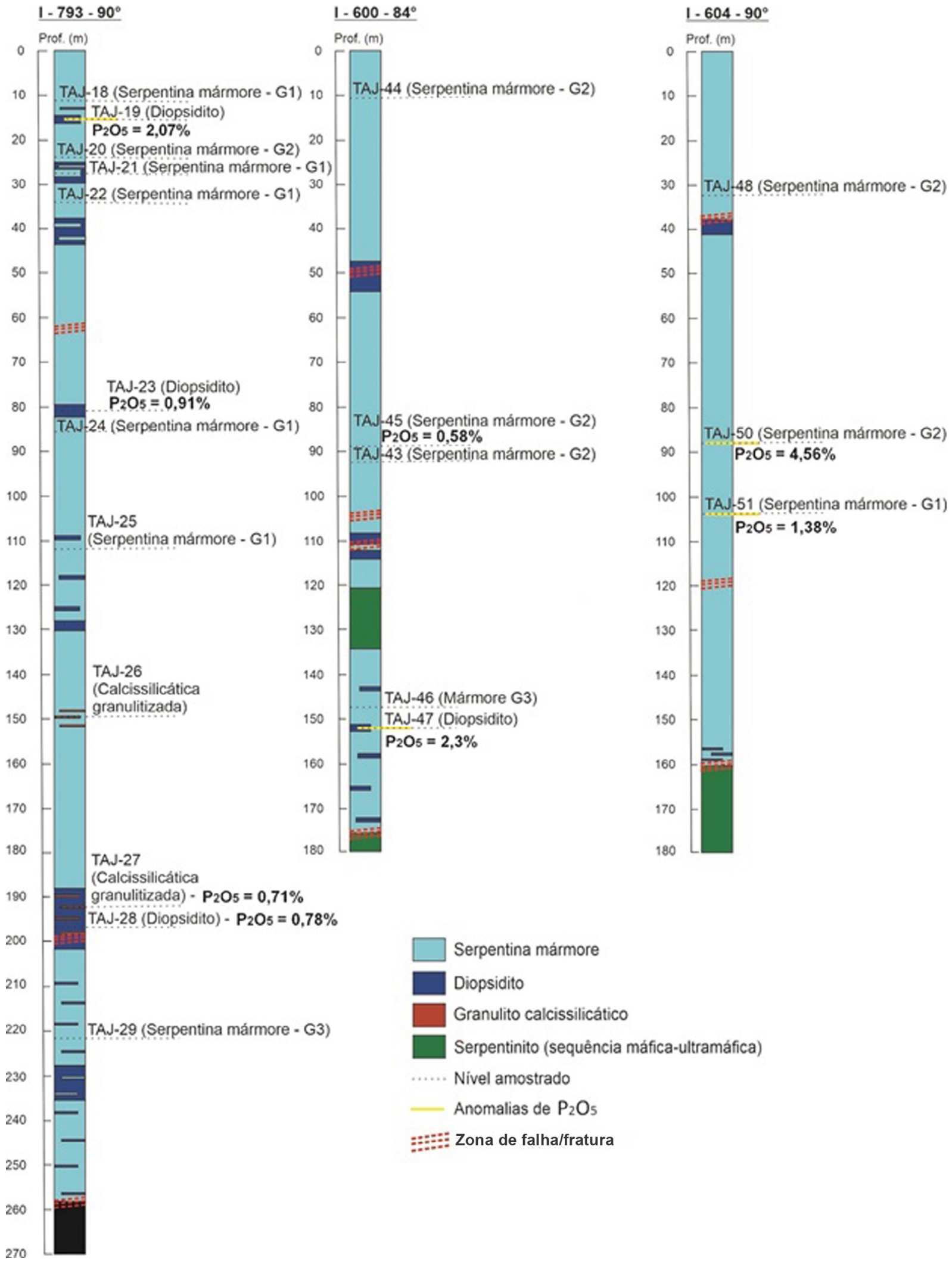

Figura 3. Distribuição vertical observada em amostras dos furos representativos de sondagem $1-793-90^{\circ}, 1-600-84^{\circ} \mathrm{e}$ I-604-90 na região de Ipueira, com destaque para valores obtidos $>1 \%$ de $\mathrm{P}_{2} \mathrm{O}_{5}$. 
observam-se bandamentos milimétricos a centimétricos, com composição intermediária entre os membros.

Amostras representativas do diopsidito mais puro (Figuras $5 \mathrm{Ae} 5 \mathrm{~B}$ ), fora das zonas de intercalação gradual, são compostas por característicos agregados de clinopiroxênios ( $95 \%)$ em diferentes proporções de diopsídio $\left(\mathrm{CaMgSi}_{2} \mathrm{O}_{6}\right)$ - hedenbergita $\left(\mathrm{CaFeSi}_{2} \mathrm{O}_{6}\right)$ e, mais raramente, de augita $(\mathrm{Ca}, \mathrm{Na})$ $(\mathrm{Mg}, \mathrm{Fe}, \mathrm{Al})\left(\mathrm{Si}_{2} \mathrm{Al}_{2} \mathrm{O}_{6}\right)$, biotita e carbonatos. Esses minerais, considerando-se o contexto em que ocorrem, são classificados como calcissilicáticos. São observadas, mais raramente, inclusões e vênulas de clorita e epidoto, filossilicatos e carbonatos entre os contatos ou truncando os cristais de diopsídio. Esses minerais encontram-se arranjados em uma microestrutura granoblástica poligonal, na qual os cristais são subidioblásticos e sem orientação, com granulometria variando de fina a média, com recristalização de até $5 \mathrm{~mm}$.

Ainda, em microscópio petrográfico (Figuras 5C e 5D), é possível observar a presença de cristais euédricos a subédricos de apatita milimétrica, compondo até $5 \%$ do valor modal. A fórmula estequiométrica da apatita é expressa como $\mathrm{Ca}_{10}\left(\mathrm{PO}_{4}\right)_{6} \mathrm{~F}_{2}$. Substituições na estrutura da apatita implicam variações na composição química desse mineral e são controladas por processos geológicos associados com cada ambiente de formação. Análises de MEV indicaram a presença de $\mathrm{Fe} \mathrm{Na}$ nas apatitas (Figura 6), que são elementos característicos na composição do carbonato-fluorapatita ou francolita $(\mathrm{Ca}, \mathrm{Na}, \mathrm{Mg})_{10}\left(\mathrm{PO}_{4}, \mathrm{CO}_{3}\right)_{6}(\mathrm{~F}, \mathrm{OH})_{2}$.
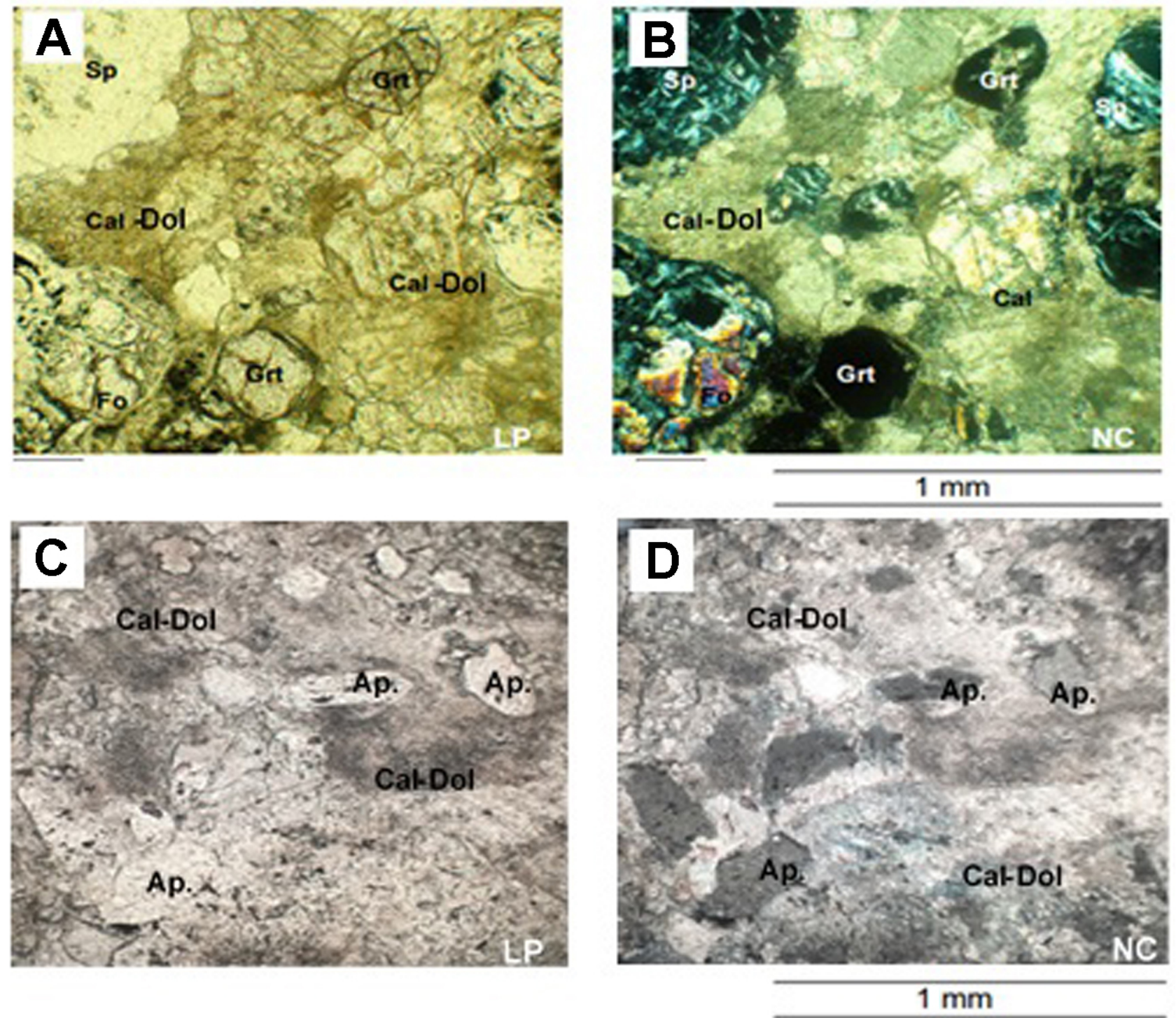

Sp: serpentina; Cal: calcita; Dol: dolomita; Ap: apatita; Grt: granada; Fo: forsterita; LP: luz polarizada; NC: nicóis cruzados.

Figura 4. (A e B) amostra MPD_02 de serpentina mármore do Grupo 1 exibindo a substituição total e parcial da olivina pela serpentina em uma matriz carbonática (calcita e, secundariamente, dolomita) e granada como acessório; (C e D) amostra TAJ-051 de serpentina-apatita mármore do Grupo 1 exibindo cristais subédricos de apatita (fluorapatita). 


\section{Rochas calcissilicáticas granulitizadas}

Este litotipo ocorre, muitas vezes, como níveis centimétricos intercalados predominantemente com diopsiditos e, mais raramente, com mármores, mostrando certa gradação composicional até a ocorrência de poucos metros de espessura de sua composição característica (Figuras 2 e 3). Exibem coloração cinza-escura e orientação incipiente.

Essas rochas são constituídas basicamente por plagioclásio, clinopiroxênio, ortopiroxênio, biotita, flogopita, biotita e, mais raramente, por feldspato alcalino, granada, possivelmente cálcica, anfibólio, quartzo e minerais opacos. Apresentam microestrutura granoblástica, na qual os cristais tendem a ser prismáticos, subdioblásticos e sem orientação. A microestrutura decussada é marcada pela presença de biotita, flogopita e anfibólio. Del Lama et al. (2001) definem a concentração de biotita, flogopita, k-feldspato nas rochas calcissilicáticas e de serpentina nos mármores como reflexo de processo metassomático pós-pico metamórfico.
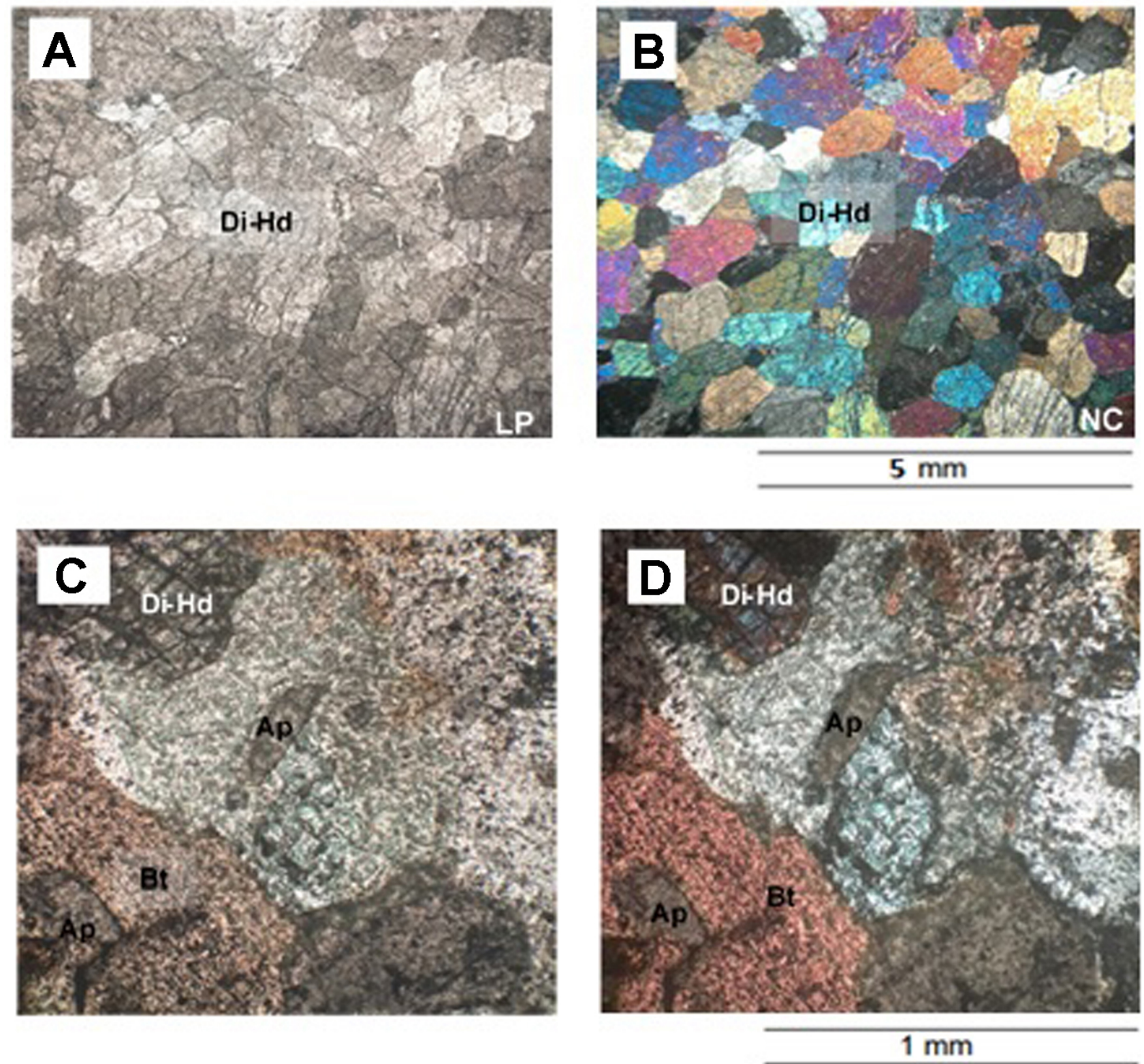

Di: diopsídio; Hd: hedenbergita; Bt: biotita.

Figura 5. (A e B) amostra TAJ-03 de diopsidito puro exibindo cristais de clinopiroxênio que formam uma microestrutura granoblástica decussada a poligonal; (C e D) amostra TAJ-19 de diopsidito com cristais de apatita subédrica envoltos por carbonato (calcita e dolomita) e biotita. 
O plagioclásio, identificado por meio da medição dos ângulos de extinção de eixos cristalográficos pelo método de Michel Levy, tem composição entre oligoclásio e albita, $\mathrm{An}_{8-20 \%}$, e constitui cerca de $55 \%$ da composição modal dessas rochas. Ocorrem frequentemente mesopertitas. Os piroxênios são predominantemente enstatita-ferrossilita $(\mathrm{Mg}, \mathrm{Fe})$ $\left(\mathrm{SiO}_{3}\right)(10 \%$ modal) e clinopiroxênios do grupo diopsídio-hedenbergita-augita (25\% modal) e, por vezes, encontram-se retrometamorfizados para anfibólio. Os cristais são geralmente subidioblásticos a xenoblásticos, algumas vezes subarredondados, e variam de granulometria fina a muito fina, com contatos diversos entre si (retos, curvos e interlobados) e, por vezes, bordas de reação (Figura 7).

Já a biotita e a flogopita (até 10\% modal) apresentam orientação preferencial incipiente e encontram-se deformadas, exibindo formas sigmoidais ou encurvadas. Esses minerais exibem frequentemente a cor marrom-avermelhada. A granada ocorre em grande parte das amostras, em proporções de cerca de $4 \%$.

\section{LITOGEOQUÍMICA}

\section{Elementos maiores e traços}

Os conteúdos de elementos maiores, traços, incluindo $\mathrm{ETR}+\mathrm{Y}$, bem como as razões obtidas entre elementos nos mármores e nas rochas calcissilicáticas do Vale do Jacurici, estão apresentados nas Tabelas 1, 2, 3 e 4. Os conteúdos de $\mathrm{SiO}_{2}$ dos mármores do Grupo 1 variam de 8,72 a 19\%, enquanto os do Grupo 2, de 11 a 23,7\%, com exceção da TAJ-43 (3,11\%). Já os conteúdos de $\mathrm{CaO}$ variam de 18,1 a $34 \%$ no Grupo 1 e de 5,71 a 44,4\% no Grupo 2. Os de $\mathrm{MgO}$ estão entre 14,3 e 27.9\% no Grupo 1 e de 5,6 a 25,4\% no Grupo 2. Os mármores do Grupo 1 apresentam teores relativamente menores de $\mathrm{Fe}_{2} \mathrm{O}_{3}(0,56-1,18 \%), \mathrm{MnO}$ $(0,04-0,15 \%)$ e $\mathrm{Al}_{2} \mathrm{O}_{3}(0,13-2,22 \%)$ com relação aos do Grupo 2, com $\mathrm{Fe}_{2} \mathrm{O}_{3}(0,76-5,03 \%), \mathrm{MnO}(0,09-0,70 \%)$ e $\mathrm{Al}_{2} \mathrm{O}_{3}(0,35-11,0 \%)$. Os valores obtidos de $\mathrm{K}_{2} \mathrm{O}$ nos Grupos 1 e 2 são, em sua maioria, abaixo do limite de detecção (s $0,01 \%$, já no Grupo 2 variam de $<0,01$ a $3,66 \%$, sendo, em sua maioria, $<1 \%$.

Para ambos os grupos, os valores de $\mathrm{Na}_{2} \mathrm{O}$ estão, em sua maioria, $<0,1 \%$. Com relação ao $\mathrm{TiO}_{2}$, a maioria das amostras do Grupo 1 apresenta teores abaixo do limite de detecção $(<0,01 \%)$, enquanto os do Grupo 2 estão entre $\leq$ 0,01 e $0,83 \%$.

Nos diopsiditos, os valores de $\mathrm{CaO}(5,03-22,9 \%)$ e $\mathrm{MgO}$ (2,71-21,1\%) são relativamente mais baixos do que os dos mármores, enquanto as variações de $\mathrm{SiO}_{2}(35,5-58,3 \%)$ apresentam valores mais altos. Os conteúdos de $\mathrm{Fe}_{2} \mathrm{O}_{3}(2.84$ $13.5 \%$ ) e $\mathrm{Al}_{2} \mathrm{O}_{3}(1.41-13.3 \%)$ são mais elevados do que nos mármores, assim como os de $\mathrm{K}_{2} \mathrm{O}(0.07-4,81 \%)$, $\mathrm{MnO}$ $(0,10-3,63 \%), \mathrm{Na}_{2} \mathrm{O}(0,18-4,40 \%)$ e $\mathrm{TiO}_{2}(0,04-1,46 \%)$.

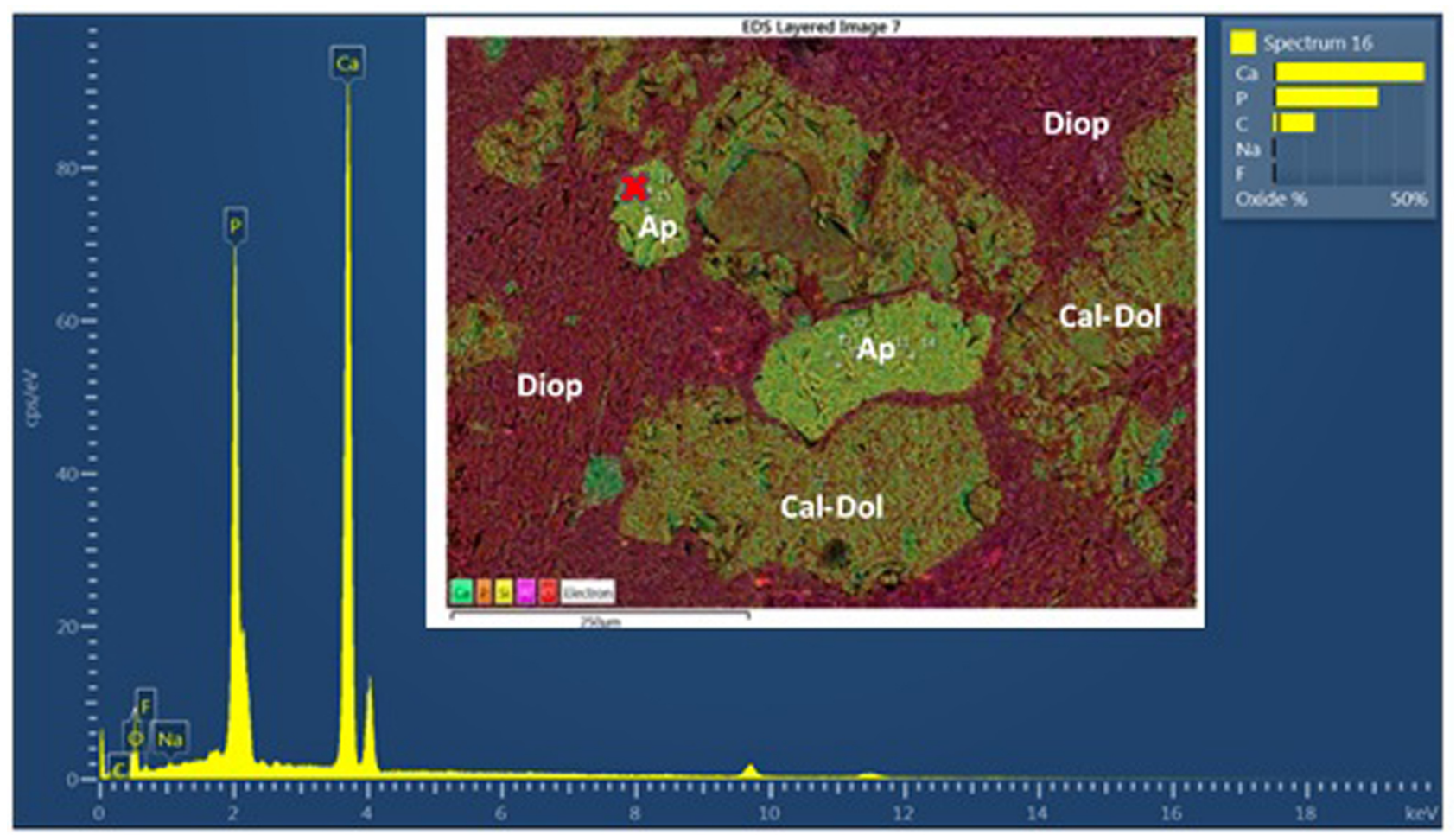

Figura 6. Fotomicrografia eletrônica e EDS (Espectrômetro de Energia Dispersiva) de apatita na amostra TAJ-19 (diopsidito), indicando a presença de $\mathrm{Na}$ e F. 
Para as rochas calcissilicáticas granulitizadas, observamos valores ainda mais baixos de $\mathrm{CaO}(1,25-10 \%)$ e $\mathrm{MgO}(1,24-8,94 \%)$, com exceção da TAJ-26, com 26,7\%. Em contrapartida, os teores de $\mathrm{SiO}_{2}(38,7-74,6 \%), \mathrm{Fe}_{2} \mathrm{O}_{3}$ $(2,47-18,9 \%), \mathrm{Al}_{2} \mathrm{O}_{3}(1,78-15,7 \%), \mathrm{K}_{2} \mathrm{O}(0,45-5,22 \%), \mathrm{Na}_{2} \mathrm{O}$ $(2,18-5,46 \%)$, com exceção da TAJ-26, com $0,15 \%$, e TiO $(0,07-2,44 \%)$ são mais altos do que os das demais litologias. Já os valores de $\mathrm{MnO}$ estão abaixo de $0,3 \%$.

Valores $\mathrm{P}_{2} \mathrm{O}_{5}>1 \%$ foram obtidos em 5 amostras estudadas. As amostras de mármores TAJ-50 e TAJ-51 apresentam conteúdo de 4,56 e $1,38 \%$ de $\mathrm{P}_{2} \mathrm{O}_{5}$, respectivamente. Nos diopsiditos, valores anômalos foram obtidos nas amostras TAJ-19 (2,07\%) e TAJ-47 (2,30\%). Todas essas
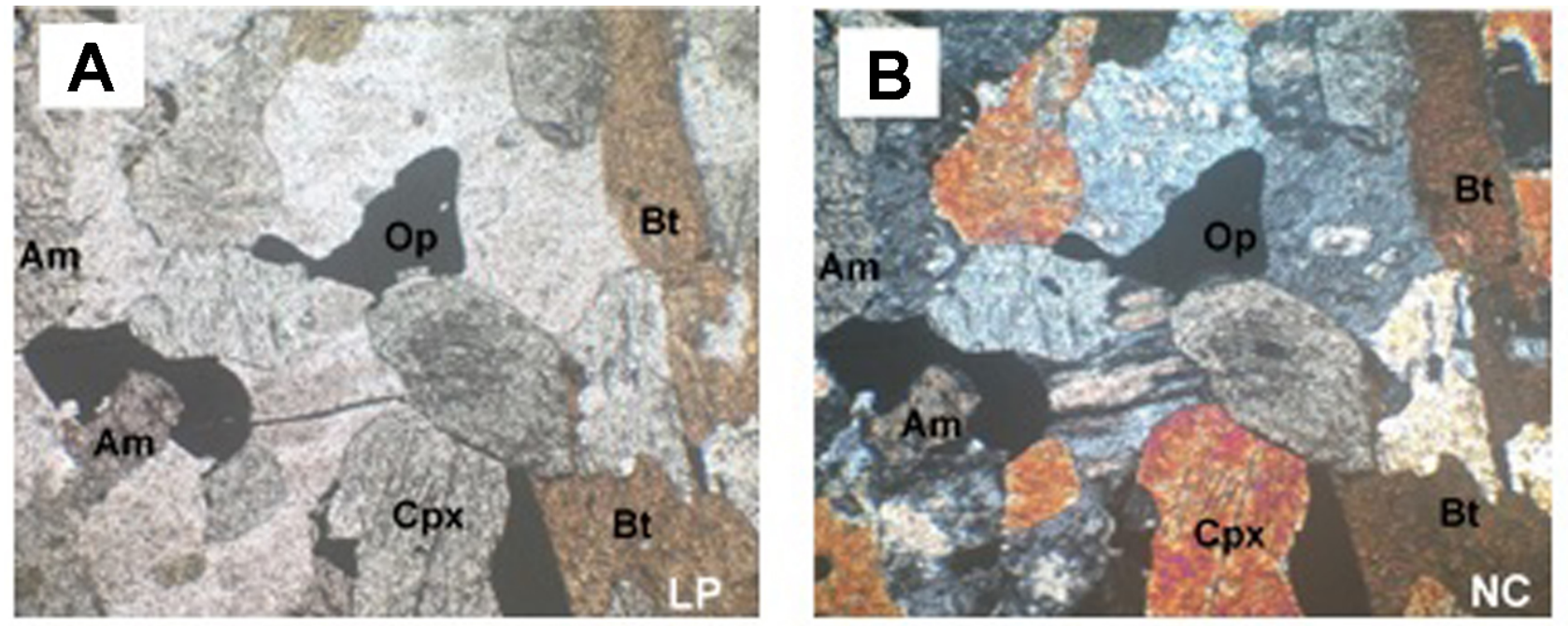

\section{$1 \mathrm{~mm}$}
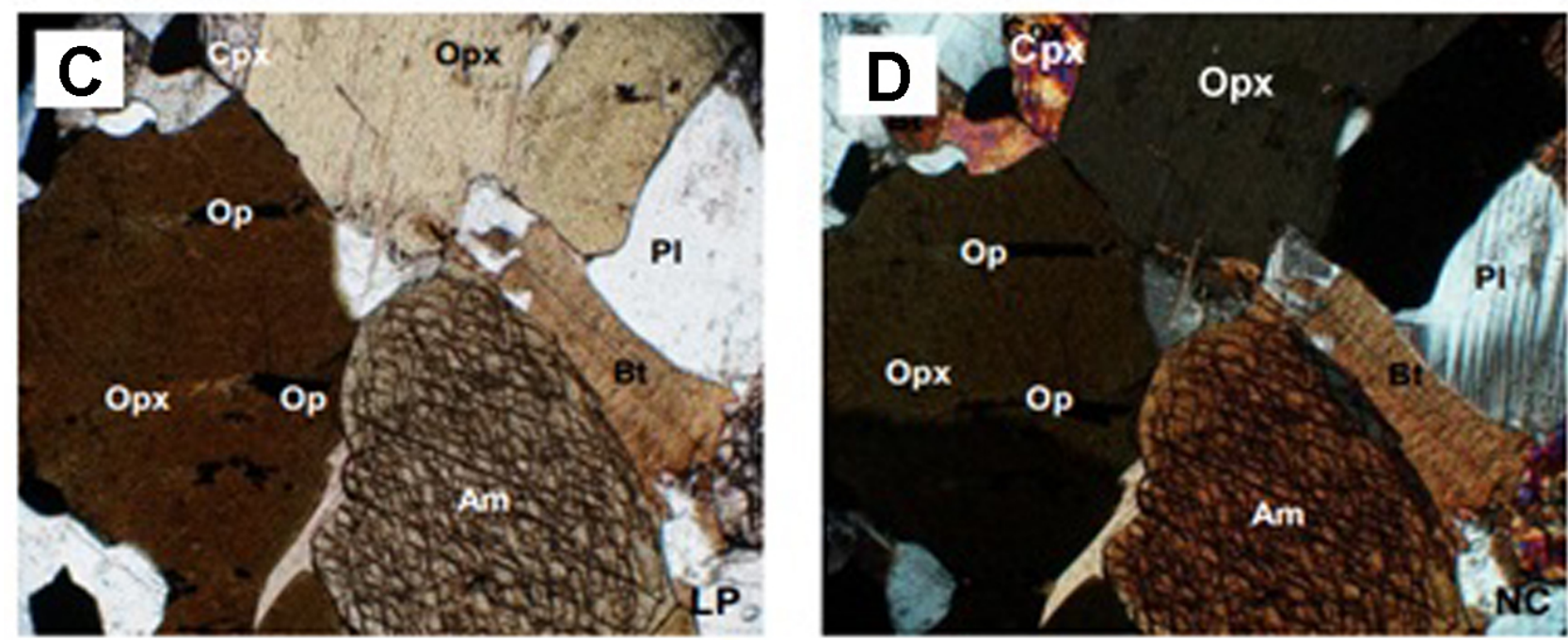

Opx: ortopiroxênio; Cpx: clinopiroxênio; Am: anfibólio; Op: opacos.

Figura 7. (A e B) amostra TAJ-04 de rocha calcissilicática granulitizadas, composta por cristais de clinopiroxênio, biotita, plagioclásio, anfibólio e minerais opacos; (B e C) amostra MI_05 de rocha calcissilicática granulitizadas, composta por cristais de clinopiroxênio, ortopiroxênio, biotita, anfibólio e minerais opacos. 
cálculo das anomalias foi o de Planavsky et al. (2010), em que: $\mathrm{Ce} / \mathrm{Ce}^{*}=\left(\mathrm{Ce}_{[\mathrm{SN}]} / 0,5 \mathrm{La}_{[\mathrm{SN}]}+0,5 \mathrm{Pr}_{[\mathrm{SN}]}\right), \mathrm{Eu} / \mathrm{Eu}^{*}=$ $\left(\mathrm{Eu}_{[\mathrm{SN}]} / 0,5 \mathrm{Sm} \mathrm{ISN}_{[\mathrm{SN}}+0,5 \mathrm{Gd}_{[\mathrm{SN}}\right), \mathrm{Y} / \mathrm{Y}^{*}=\left(\mathrm{Y}_{[\mathrm{SN}]} / 0,5 \mathrm{Dy} \mathrm{ISN}_{[\mathrm{SN}}+0,5 \mathrm{Ho}_{[\mathrm{SN}}\right)$ e $\mathrm{Gd} / \mathrm{Gd}^{*}=\left(\mathrm{Gd}_{[\mathrm{SN}]} / 0,5 \mathrm{Eu}_{[\mathrm{SN}]}+0,5 \mathrm{~Tb}_{[\mathrm{SN}]}\right)$.
Os mármores do Grupo 1 (Figura 8A) apresentam fraco enriquecimento de elementos terras raras leves (ETRL) em relação aos pesados (ETRP), conforme relação média $\mathrm{Pr} / \mathrm{Yb}_{[\mathrm{SN}]}$ $=1,83$ e somatório $\Sigma \mathrm{ETR}+\mathrm{Y}=64,8 \mathrm{ppm}$, configurando um

Tabela 1. Composição dos elementos maiores, traços, ETR + Y, anomalias e razões nos mármores do Grupo 1.

\begin{tabular}{|c|c|c|c|c|c|c|c|c|c|c|c|c|c|}
\hline Amostr & & $\begin{array}{l}\text { TAJ- } \\
18 A \\
\end{array}$ & $\begin{array}{l}\text { TAJ- } \\
22 A \\
\end{array}$ & $\begin{array}{l}\text { TAJ- } \\
24 A\end{array}$ & $\begin{array}{l}\text { TAJ- } \\
25 A\end{array}$ & $\begin{array}{l}\text { TAJ- } \\
38 A\end{array}$ & $\begin{array}{l}\text { TAJ- } \\
51 A\end{array}$ & MI-01 & MI-07 & $\begin{array}{c}\text { MPD- } \\
01\end{array}$ & $\begin{array}{c}\text { MPD- } \\
02\end{array}$ & $\begin{array}{c}\text { MPD- } \\
04\end{array}$ & $\begin{array}{c}\text { MPD- } \\
05\end{array}$ \\
\hline \multirow{12}{*}{ 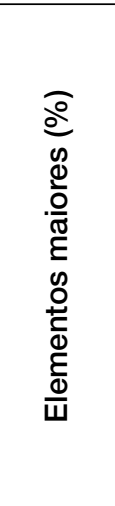 } & $\mathrm{SiO}_{2}$ & 17,25 & 19,01 & 14,11 & 11,89 & 16,47 & 15,64 & 12,29 & 16,33 & 8,72 & 12,52 & 14,88 & 9,81 \\
\hline & $\mathrm{TiO}_{2}$ & $<0,01$ & 0,01 & $<0,01$ & 0,01 & 0,07 & 0,04 & 0,01 & $<0,01$ & $<0,01$ & 0,02 & $<0,01$ & $<0,01$ \\
\hline & $\mathrm{Al}_{2} \mathrm{O}_{3}$ & 0,13 & 1,26 & 0,81 & 1,09 & 1,22 & 0,16 & 0,98 & 0,50 & 0,52 & 2,22 & 0,24 & 0,44 \\
\hline & $\mathrm{Fe}_{2} \mathrm{O}_{3}$ & 1,50 & 1,60 & 0,81 & 0,90 & 1,07 & 0,62 & 1,18 & 0,72 & 0,70 & 0,97 & 0,56 & 0,62 \\
\hline & $\mathrm{MnO}$ & 0,10 & 0,10 & 0,09 & 0,09 & 0,15 & 0,12 & 0,06 & 0,04 & 0,04 & 0,09 & 0,11 & 0,11 \\
\hline & $\mathrm{MgO}$ & 27,98 & 24,93 & 18,99 & 16,78 & 16,61 & 19,02 & 14,31 & 15,75 & 19,64 & 20,30 & 21,46 & 18,70 \\
\hline & $\mathrm{CaO}$ & 18,15 & 18,37 & 28,93 & 29,96 & 32,63 & 28,30 & 32,90 & 34,08 & 30,21 & 30,96 & 27,75 & 30,31 \\
\hline & $\mathrm{Na}_{2} \mathrm{O}$ & 0,02 & 0,08 & 0,02 & 0,03 & 0,11 & 0,02 & & 0,02 & 0,01 & 0,02 & 0,06 & 0,03 \\
\hline & $\mathrm{K}_{2} \mathrm{O}$ & 0,01 & 0,36 & $<0,01$ & $<0,01$ & 0,34 & 0,01 & $<0,01$ & $<0,01$ & $<0,01$ & $<0,01$ & 0,02 & $<0,01$ \\
\hline & $\mathrm{P}_{2} \mathrm{O}_{5}$ & $<0,01$ & $<0,01$ & $<0,01$ & $<0,01$ & 0,14 & 1,38 & $<0,01$ & 0,09 & $<0,01$ & $<0,01$ & $<0,01$ & $<0,01$ \\
\hline & LOI & 35,16 & 32,01 & 33,07 & 35,42 & 31,07 & 30,66 & 35,23 & 32,68 & 38,28 & 33,49 & 33,54 & 38,38 \\
\hline & TOTAL & 100,30 & 97,73 & 96,83 & 96,17 & 99,88 & 95,97 & 96,99 & 100,21 & 98,12 & 100,59 & 98,62 & 98,40 \\
\hline \multirow{9}{*}{ 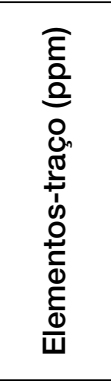 } & $\mathrm{Ba}$ & $<10$ & 377,00 & 133,00 & 121,00 & 247,00 & $<10$ & 105,00 & 11,00 & 30,00 & 33,00 & 15,00 & 101,00 \\
\hline & $\mathrm{Sr}$ & 38,00 & 39,00 & 239,00 & 266,00 & 240,00 & 88,00 & 155,00 & 66,00 & 42,00 & 48,00 & 55,00 & 64,00 \\
\hline & $\mathrm{Zr}$ & 10,00 & 10,00 & 10,00 & 10,00 & 27,00 & $<10$ & 2 & U & 1,00 & 1,00 & 1,00 & 1,00 \\
\hline & $\mathrm{Zn}$ & 19,00 & $<5$ & $<5$ & $<5$ & $<5$ & 114,00 & 27,00 & 10,00 & 14,00 & 12,00 & 15,00 & 21,00 \\
\hline & $\mathrm{Cu}$ & $<5$ & $<5$ & $<5$ & $<5$ & $<5$ & $<5$ & 2,00 & & 3,00 & 1,00 & $<1$ & 2,00 \\
\hline & $\mathrm{Ni}$ & 20,00 & 29,00 & 30,00 & 23,00 & 28,00 & 28,00 & 15,00 & 10,00 & 13,00 & 20,00 & 11,00 & 15,00 \\
\hline & v & $<5$ & $<5$ & $<5$ & $<5$ & 5,00 & $<5$ & 7,00 & 7,00 & 5,00 & 6,00 & 4,00 & 5,00 \\
\hline & $\mathrm{Hf}$ & 0,05 & 0,12 & 0,07 & 0,12 & 0,68 & 0,13 & . & - & - & - & - & - \\
\hline & Co & 3,90 & 9,10 & 3,80 & 3,60 & 4,60 & 2,10 & 5,00 & 4,00 & 5,00 & 5,00 & 4,00 & 4,00 \\
\hline \multirow{16}{*}{ 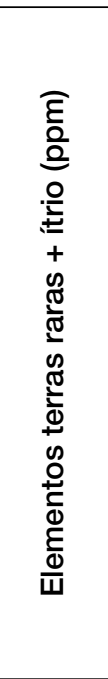 } & $\mathrm{Y}$ & 13,69 & 13,74 & 14,45 & 17,06 & 24,43 & 13,31 & 22,54 & 16,11 & 17,35 & 10,17 & 15,17 & 14,01 \\
\hline & La & 20,10 & 15,50 & 23,60 & 25,70 & 20,10 & 10,20 & 27,50 & 17,20 & 13,20 & 15,50 & 14,70 & 11,50 \\
\hline & $\mathrm{Ce}$ & 21,20 & 10,20 & 29,00 & 31,20 & 15,00 & 6,80 & 21,80 & 7,70 & 3,70 & 5,60 & 4,00 & 3,60 \\
\hline & Pr & 2,75 & 1,65 & 4,31 & 4,36 & 2,91 & 1,29 & 3,82 & 1,67 & 1,25 & 1,30 & 1,21 & 1,03 \\
\hline & $\mathrm{Nd}$ & 9,90 & 6,00 & 16,20 & 17,00 & 11,30 & 5,10 & 16,40 & 7,40 & 5,80 & 5,90 & 5,50 & 4,80 \\
\hline & $\mathrm{Sm}$ & 1,00 & 1,10 & 2,40 & 2,40 & 2,10 & 0,80 & 2,30 & 1,00 & 0,80 & 0,70 & 0,70 & 0,70 \\
\hline & $\mathrm{Eu}$ & 0,37 & 0,33 & 0,55 & 0,64 & 0,50 & 0,27 & 0,4 & 0,19 & 0,16 & 0,10 & 0,13 & 0,12 \\
\hline & $\mathrm{Gd}$ & 1,06 & 1,17 & 1,88 & 2,46 & 2,41 & 1,07 & 2,50 & 1,33 & 1,30 & 0,91 & 1,22 & 1,06 \\
\hline & $\mathrm{Tb}$ & 0,15 & 0,18 & 0,21 & 0,29 & 0,34 & 0,15 & 0,2 & 0,07 & 0,10 & 0,05 & 0,07 & 0,05 \\
\hline & Dy & 1,03 & 1,12 & 1,35 & 1,65 & 2,02 & 0,86 & 1,8 & 1,17 & 1,18 & 0,69 & 0,97 & 0,88 \\
\hline & Ho & 0,22 & 0,26 & 0,30 & 0,35 & 0,43 & 0,22 & 0,3 & 0,18 & 0,19 & 0,07 & 0,16 & 0,14 \\
\hline & $\mathrm{Er}$ & 0,64 & 0,65 & 0,84 & 0,88 & 1,11 & 0,70 & 1,09 & 0,73 & 0,72 & 0,41 & 0,65 & 0,59 \\
\hline & $\mathrm{Tm}$ & 0,08 & 0,09 & 0,14 & 0,14 & 0,14 & 0,06 & $<0,05$ & $<0,05$ & $<0,05$ & $<0,05$ & $<0,05$ & $<0,05$ \\
\hline & $\mathrm{Yb}$ & 0,30 & 0,40 & 0,40 & 0,50 & 0,6 & 0,30 & & & 0,40 & 0,20 & 0,30 & 0,30 \\
\hline & Lu & $<0,05$ & 0,07 & 0,05 & 0,08 & 0,0 & 0,05 & $<0$ & $<0$ & $<0,05$ & $<0,05$ & $<0,05$ & $<0,05$ \\
\hline & $\Sigma \mathrm{ETR}+\mathrm{Y}$ & 72,49 & 52,46 & 95,68 & 104,71 & 83,47 & 41,18 & & 55,15 & 46,15 & 41,60 & 44,78 & 38,78 \\
\hline \multirow{6}{*}{ 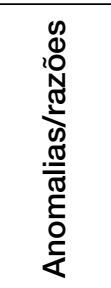 } & $\begin{array}{c}\mathrm{Pr} / \\
\mathrm{Yb}\left[_{\mathrm{SNl}}\right.\end{array}$ & 2,93 & 1,32 & 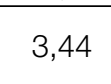 & 2,78 & 1,55 & 1 & 1,74 & 1,33 & 1,00 & 2,08 & 1 & 0 \\
\hline & $\mathrm{Ce} / \mathrm{Ce}^{*}$ & 0,64 & 0,43 & 0,66 & 0,67 & 0,44 & 0,41 & 0,4 & 0,30 & 0,19 & 0,25 & 0,19 & 0,22 \\
\hline & $Y / Y^{*}$ & 2,29 & 2,03 & 1,81 & 1,79 & 2,09 & 2,43 & 2,40 & 2,76 & 2,90 & 3,45 & 3,05 & 3,15 \\
\hline & $\mathrm{Eu} / \mathrm{Eu}^{*}$ & 1,68 & 1,36 & 1,22 & 1,23 & 1,03 & 1,34 & 0,88 & 0,76 & 0,70 & 0,58 & 0,62 & 0,63 \\
\hline & $\mathrm{Gd} / \mathrm{Gd}^{\star}$ & 0,85 & 0,93 & 1,03 & 1,09 & 1,15 & 1,03 & 1,56 & 2,14 & 2,01 & 2,48 & 2,48 & 2,59 \\
\hline & $\mathrm{Y} / \mathrm{Ho}$ & 62,23 & 52,85 & 48,17 & 48,74 & 56,81 & 60,50 & 75,13 & 89,50 & 91,32 & 145,29 & 94,81 & 100,07 \\
\hline
\end{tabular}


padrão tabular. As amostras apresentam pronunciada anomalia negativa de $\mathrm{Ce}\left(\mathrm{Ce} / \mathrm{Ce}^{*}=0,19-0,67\right)$ e positiva de $\mathrm{Y}\left(\mathrm{Y} / \mathrm{Y}^{*}\right.$ $=1,81-3,45)$. As anomalias de Eu variam entre positivas e negativas $\left(\mathrm{Eu} / \mathrm{Eu}^{*}=0,58-1,68\right)$. Anomalias positivas de $\mathrm{Gd}$ também foram identificadas $\left(\mathrm{Gd} / \mathrm{Gd}^{*}=0,85-2,59\right)$, sendo que apenas duas amostras apresentam $\mathrm{Gd} / \mathrm{Gd}^{*}<1$, mesmo com o efeito mútuo do elemento vizinho $(\mathrm{Eu})$.
Os mármores do Grupo 2 (Figura 8B), por sua vez, apresentam maior enriquecimento de ETRL sobre ETRP $\left(\mathrm{Pr} / \mathrm{Yb}_{[\mathrm{SN}]}=2,93\right)$, com maiores valores de $\Sigma \mathrm{ETR}+\mathrm{Y}$ $=133 \mathrm{ppm}$. As anomalias negativas de $\mathrm{Ce}\left(\mathrm{Ce} / \mathrm{Ce}^{*}=\right.$ $0,65-0,99)$ e positivas de $\mathrm{Y}\left(\mathrm{Y} / \mathrm{Y}^{*}=1,25-2,12\right)$, apesar de menos pronunciadas do que as apresentadas pelas amostras do Grupo 1, são observadas. Similarmente às

Tabela 2. Composição dos elementos maiores, traços, ETR + Y, anomalias e razões nos mármores do Grupo 2.

\begin{tabular}{|c|c|c|c|c|c|c|c|c|c|c|c|c|c|c|c|}
\hline \multicolumn{2}{|c|}{ Amostra } & $\begin{array}{l}\text { TAJ- } \\
10 A\end{array}$ & $\begin{array}{l}\text { TAJ- } \\
13 A\end{array}$ & $\begin{array}{l}\text { TAJ- } \\
20 A\end{array}$ & $\begin{array}{l}\text { TAJ- } \\
43 A\end{array}$ & $\begin{array}{l}\text { TAJ- } \\
44 A\end{array}$ & $\begin{array}{l}\text { TAJ- } \\
48 A\end{array}$ & $\begin{array}{l}\text { TAJ- } \\
50 A\end{array}$ & $\begin{array}{l}\text { TAJ- } \\
57 A\end{array}$ & MI-04 & $\begin{array}{c}\text { MM- } \\
11\end{array}$ & $\begin{array}{c}\text { MM- } \\
15\end{array}$ & $\begin{array}{c}\text { MM- } \\
13\end{array}$ & $\begin{array}{c}\text { MM- } \\
19\end{array}$ & $\begin{array}{l}\text { MM- } \\
19-1\end{array}$ \\
\hline \multirow{12}{*}{ 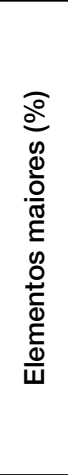 } & $\mathrm{SiO}_{2}$ & 17,78 & 11,6 & 11,06 & 3,11 & 15,53 & 21,29 & 19,14 & 12,04 & 16,1 & 13,84 & 12,73 & 23,79 & 21,35 & 21,12 \\
\hline & $\mathrm{TiO}_{2}$ & 0,18 & 0,03 & $<0,01$ & 0,02 & $<0,01$ & 0,83 & 0,4 & 0,13 & 0,23 & 0,22 & 0,24 & 0,8 & $<0,01$ & $<0,01$ \\
\hline & $\mathrm{Al}_{2} \mathrm{O}_{3}$ & 1,51 & 0,75 & 0,46 & 0,59 & 0,88 & 11 & 4,54 & 2 & 3,17 & 2,62 & 3,09 & 7,06 & 0,36 & 0,35 \\
\hline & $\mathrm{Fe}_{2} \mathrm{O}_{3}$ & 2,22 & 0,96 & 2,8 & 0,76 & 1,38 & 1,18 & 1,94 & 1,44 & 5,03 & 2,71 & 2,91 & 4,41 & 1,56 & 1,54 \\
\hline & $\mathrm{MnO}$ & 0,31 & 0,15 & 0,17 & 0,15 & 0,11 & 0,12 & 0,14 & 0,1 & 0,12 & 0,7 & 0,09 & 0,14 & 0,12 & 0,12 \\
\hline & $\mathrm{MgO}$ & 17,68 & 5,6 & 22,67 & 19,22 & 25,46 & 23,09 & 18,76 & 21,98 & 14,98 & 16,89 & 17,5 & 21,95 & 15,01 & 14,79 \\
\hline & $\mathrm{CaO}$ & 29,55 & 44,45 & 22,72 & 28,85 & 22,02 & 14,21 & 23,71 & 25,13 & 30,06 & 27,91 & 28,23 & 16,17 & 32,48 & 32,25 \\
\hline & $\mathrm{Na}_{2} \mathrm{O}$ & 0,03 & 0,05 & 0,04 & 0,02 & 0,03 & 0,18 & 0,04 & 0,01 & 0,06 & 0,01 & 0,01 & 0,12 & 0,02 & 0,02 \\
\hline & $\mathrm{K}_{2} \mathrm{O}$ & 0,21 & 0,39 & 0,05 & $<0,01$ & $<0,01$ & 3,08 & 0,71 & 0,08 & 0,69 & $<0,01$ & $<0,01$ & 3,66 & 0,15 & 0,16 \\
\hline & $\mathrm{P}_{2} \mathrm{O}_{5}$ & 0,16 & $<0,01$ & $<0,01$ & $<0,01$ & $<0,01$ & $<0,01$ & 4,56 & $<0,01$ & 0,35 & $<0,01$ & 0,47 & $<0,01$ & $<0,01$ & $<0,01$ \\
\hline & LOI & 30,72 & 35,06 & 38,15 & 44,4 & 36,5 & 26,87 & 22,68 & 33,23 & 29,26 & 32,17 & 32,94 & 22,88 & 30,47 & 30,41 \\
\hline & TOTAL & 100,35 & 99,05 & 98,14 & 97,14 & 101,94 & 101,86 & 96,62 & 96,15 & 100,05 & 97,09 & 98,22 & 100,99 & 101,54 & 100,78 \\
\hline \multirow{9}{*}{ 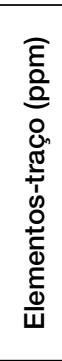 } & $\mathrm{Ba}$ & 368 & 227 & 33 & 202 & $<10$ & 1.670 & 725 & 150 & 780 & 45 & 120 & 3.189 & 71 & 78 \\
\hline & $\mathrm{Sr}$ & 103 & 777 & 51 & 46 & 37 & 22 & 265 & 301 & 179 & 235 & 117 & 114 & 396 & 396 \\
\hline & $\mathrm{Zr}$ & 20 & 11 & 10 & 10 & 10 & 303 & 215 & 34 & 7 & 1 & 1 & 1 & 1 & 1 \\
\hline & $\mathrm{Zn}$ & 57 & $<5$ & $<5$ & $<5$ & $<5$ & 21 & 765 & 46 & 22 & 885 & 24 & 35 & 8 & 8 \\
\hline & $\mathrm{Cu}$ & $<5$ & 5 & 6 & $<5$ & $<5$ & 9 & 375 & 6 & 3 & 8 & 5 & 24 & 3 & 4 \\
\hline & $\mathrm{Ni}$ & 38 & 28 & 29 & 27 & 24 & 19 & 19 & 52 & 25 & 55 & 22 & 33 & 9 & 10 \\
\hline & V & 18 & 16 & $<5$ & 40 & $<5$ & 51 & 49 & $<5$ & & 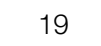 & 28 & 75 & 4 & 5 \\
\hline & $\mathrm{Hf}$ & 0,55 & 0,43 & 0,08 & 0,11 & 0,06 & 6,57 & 4,23 & 0,91 & - & - & - & - & - & - \\
\hline & Co & & & 10,3 & & & & & & 17 & 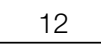 & 12 & 10 & . & 5 \\
\hline \multirow{16}{*}{ 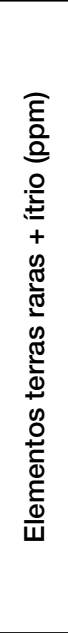 } & $Y$ & 12,5 & 31,59 & 31 & 9,44 & 15,88 & 17,29 & 19 & 15,61 & 8,39 & 6,31 & 6,32 & 17,79 & 13,07 & 12,82 \\
\hline & La & 14,8 & 85,8 & 66,9 & 19,1 & 22,2 & 44,2 & 40,2 & 29,4 & 13,1 & 3 & 11,9 & 24,6 & 44,5 & 43,5 \\
\hline & $\mathrm{Ce}$ & 15,5 & 120,5 & 104 & 21 & 25,3 & 68,9 & 65,8 & 42,6 & 22,8 & 46,1 & 12,6 & 26,4 & 53 & 51,7 \\
\hline & $\operatorname{Pr}$ & 1,88 & 13,05 & 11,57 & 2,38 & 3,09 & 7,95 & 8,44 & 5,39 & 2,09 & 3,77 & 1,25 & 2,78 & 5,28 & 5,26 \\
\hline & $\mathrm{Nd}$ & 7,5 & 42,4 & 41 & 8,7 & 11,7 & 30,1 & 32,9 & 20,7 & & 1 & 5,6 & 11,7 & 18,6 & 18,3 \\
\hline & $\mathrm{Sm}$ & 1,3 & 5,8 & 6 & 1,5 & 2,2 & 4,3 & 5,5 & 3,1 & 1,5 & 1,7 & 1,1 & 2,2 & 2,2 & 2,1 \\
\hline & $\mathrm{Eu}$ & 0,34 & 0,91 & 0,72 & 0,33 & 0,27 & 0,8 & 1,4 & 0,67 & 0,4 & 0,31 & 0,23 & 0,64 & 0,47 & 0,49 \\
\hline & Gd & 1,62 & 5,03 & 5,04 & 1,21 & 2,18 & 3,67 & 4,42 & 2,1 & 1,62 & 1,53 & 1,28 & 2,78 & 2,02 & 2,04 \\
\hline & $\mathrm{Tb}$ & 0,24 & 0,67 & 0,57 & 0,18 & 0,32 & 0,41 & 0,58 & 0,28 & 0,14 & 0 & 0,09 & 0,3 & 0,16 & 0,15 \\
\hline & Dy & 1,53 & 3,57 & 2,99 & 0,96 & 1,89 & 2,3 & 2,76 & 1,52 & 1, & 0,98 & 1,08 & 2,38 & 1,34 & 1,29 \\
\hline & Ho & 0,32 & 0,69 & 0,55 & 0,18 & 0,39 & 0,36 & 0,53 & 0,29 & 0,19 & 0,11 & 0,14 & 0,43 & 0,17 & 0,17 \\
\hline & $\mathrm{Er}$ & 0,98 & 1,89 & 1,5 & 0,55 & 0,97 & 0,93 & 1,21 & 0,83 & 0,68 & 0,45 & 0,52 & 1,46 & 0,74 & 0,72 \\
\hline & $\mathrm{Tm}$ & 0,16 & 0,25 & 0,18 & 0,13 & 0,14 & 0,12 & 0,16 & 0,15 & $<0,05$ & $<0,05$ & $<0,05$ & 0,1 & $<0,05$ & $<0,05$ \\
\hline & $\mathrm{Yb}$ & 0,8 & 1,1 & 0,8 & 0,3 & 0,7 & 0,4 & 0,7 & 0,4 & 0,6 & 0,4 & 0,4 & 1,3 & 0,4 & 0,5 \\
\hline & Lu & 0,11 & 0,14 & 0,1 & 0,06 & 0,11 & 0,07 & 0,11 & 0,06 & $<0,05$ & $<0,05$ & $<0,05$ & 0,09 & $<0,05$ & $<0,05$ \\
\hline & $\Sigma$ ETR+Y & 59,58 & 313,39 & 272,92 & 66,02 & 87,34 & 181,8 & 183,71 & 123,1 & 61,44 & 107,27 & 42,51 & 94,95 & 141,95 & 139,04 \\
\hline \multirow{7}{*}{ 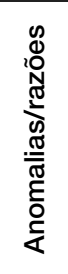 } & $\mathrm{Pr} / \mathrm{Yb}_{[\mathrm{SN}]}$ & 0,75 & 3,79 & 4,62 & 2,53 & 1,41 & 6,35 & 3,85 & 4,3 & 1,11 & 3,01 & 1 & 0,68 & 4,22 & 3,36 \\
\hline & $\mathrm{Ce} / \mathrm{Ce}^{*}$ & 0,65 & 0,81 & 0,85 & 0,69 & 0,68 & 0,84 & 0,82 & 0,78 & 0,99 & 0,91 & 0,7 & 0,69 & 0,76 & 0,75 \\
\hline & $Y / Y^{*}$ & 1,42 & 1,6 & 1,92 & 1,81 & 1,48 & 1,5 & 1,25 & 1,87 & 1,31 & 1,46 & 1,26 & 1,4 & 2,11 & 2,12 \\
\hline & $\mathrm{Eu} / \mathrm{Eu}^{*}$ & 1,08 & 0,79 & 0,62 & 1,15 & 0,58 & 0,95 & 1,34 & 1,23 & 1,2 & 0,9 & 0,9 & 1,19 & 1,05 & 1,11 \\
\hline & $\mathrm{Gd} / \mathrm{Gd}^{*}$ & 1,11 & 1,26 & 1,54 & 0,97 & 1,41 & 1,24 & 0,93 & 0,92 & 1,26 & 1,53 & 1,67 & 1,22 & 1,35 & 1,35 \\
\hline & Y/Ho & 39,06 & 45,78 & 56,36 & 52,44 & 40,72 & 48,03 & 35,85 & 53,83 & 44,16 & 57,36 & 45,14 & 41,37 & 76,88 & 75,41 \\
\hline & $\mathrm{Eu} / \mathrm{Sm}$ & 0,26 & 0,16 & 0,12 & 0,22 & 0,12 & 0,19 & 0,25 & 0,22 & 0,27 & 0,18 & 0,21 & 0,29 & 0,21 & 0,23 \\
\hline
\end{tabular}


amostras do Grupo 1, são observadas anomalias de Eu $\left(\mathrm{Eu} / \mathrm{Eu}^{*}=0,58-1,34\right)$ oscilantes entre positivas e negativas. Anomalias levemente positivas de Gd foram identificadas $\left(\mathrm{Gd} / \mathrm{Gd}^{*}=0,93-1,67\right)$.
Nas rochas calcissilicáticas é observado enriquecimento de ETRL, conforme relação média de $\mathrm{Pr} / \mathrm{Yb}_{[\mathrm{SN}]}=2,49$ nos diopsiditos e de 3,57 nas granulitizadas. Nestas, o somatório $\Sigma \mathrm{ETR}+\mathrm{Y}=231 \mathrm{ppm}$ foi o maior obtido, e a maioria

Tabela 3. Composição dos elementos maiores, traços, ETR + Y, anomalias e razões nos diopsiditos.

\begin{tabular}{|c|c|c|c|c|c|c|c|c|c|c|c|c|}
\hline \multicolumn{2}{|c|}{ Amostra } & $\begin{array}{l}\text { TAJ- } \\
03 A \\
\end{array}$ & $\begin{array}{l}\text { TAJ- } \\
19 A \\
\end{array}$ & $\begin{array}{l}\text { TAJ- } \\
23 A \\
\end{array}$ & $\begin{array}{l}\text { TAJ- } \\
28 A \\
\end{array}$ & $\begin{array}{l}\text { TAJ- } \\
39 A \\
\end{array}$ & $\begin{array}{l}\text { TAJ- } \\
47 A \\
\end{array}$ & $\begin{array}{c}\text { MI- } \\
02.1 \\
\end{array}$ & MM-02 & MM-09 & MM-12 & MM-16 \\
\hline \multirow{12}{*}{ 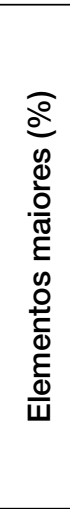 } & $\mathrm{SiO}_{2}$ & 51,86 & 35,58 & 44,85 & 58,36 & 51,41 & 42,85 & 44,91 & 40,97 & 51,48 & 55,01 & 50,03 \\
\hline & $\mathrm{TiO}_{2}$ & 0,19 & 0,57 & 0,69 & 1,46 & 0,51 & 0,81 & 0,54 & 1,45 & 0,15 & 0,12 & 0,15 \\
\hline & $\mathrm{Al}_{2} \mathrm{O}_{3}$ & 5,72 & 10,01 & 8,17 & 13,34 & 6,33 & 10,41 & 8,48 & 13,19 & 2,67 & 2,11 & 5,22 \\
\hline & $\mathrm{Fe}_{2} \mathrm{O}_{3}$ & 3,56 & 2,84 & 2,88 & 6,44 & 6,62 & 4,12 & 7,53 & 13,56 & 4,93 & 5,69 & 4,35 \\
\hline & $\mathrm{MnO}$ & 0,36 & 0,12 & 0,12 & 0,09 & 0,17 & 0,1 & 0,11 & 0,18 & 3,63 & 0,21 & 0,22 \\
\hline & $\mathrm{MgO}$ & 13,44 & 21,14 & 11,41 & 2,71 & 15,45 & 19,16 & 19,5 & 9,05 & 12,69 & 17,42 & 14,74 \\
\hline & $\mathrm{CaO}$ & 22,98 & 13 & 20,11 & 5,03 & 18,21 & 10,46 & 11,33 & 20,76 & 20,68 & 19,43 & 22,3 \\
\hline & $\mathrm{Na}_{2} \mathrm{O}$ & 0,31 & 0,43 & 0,87 & 4,4 & 0,55 & 1,08 & 1,68 & 0,52 & 0,27 & 0,22 & 0,18 \\
\hline & $\mathrm{K}_{2} \mathrm{O}$ & 0,55 & 1,5 & 1,6 & 4,81 & 1,69 & 1,61 & 0,65 & 0,5 & 0,73 & 0,5 & 0,07 \\
\hline & $\mathrm{P}_{2} \mathrm{O}_{5}$ & 0,46 & 2,07 & 0,91 & 0,78 & $<0,01$ & 2,3 & 0,72 & 0,26 & 1 & $<0,01$ & 0,09 \\
\hline & LOI & 1,32 & 13,35 & 5,2 & 0,38 & 1,97 & 6,63 & 2,31 & 1,23 & 0,76 & 1,21 & 1,49 \\
\hline & TOTAL & 100,75 & 100,61 & 96,81 & 97,8 & 102,92 & 99,53 & 97,76 & 101,67 & 98,99 & 101,93 & 98,84 \\
\hline \multirow{9}{*}{ 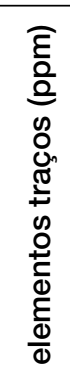 } & $\mathrm{Ba}$ & 188 & 1.871 & 3.184 & 3.464 & 859 & 2.212 & 152 & 171 & 63 & 244 & 34 \\
\hline & $\mathrm{Sr}$ & 57 & 223 & 2.109 & 1.358 & 125 & 253 & 49 & 45 & 25 & 10 & 21 \\
\hline & $\mathrm{Zr}$ & 50 & 311 & 178 & 385 & 137 & 341 & 10 & 12 & 3 & 3 & 12 \\
\hline & $\mathrm{Zn}$ & 62 & 52 & $<5$ & 116 & 52 & 17 & 5 & 69 & 34 & 27 & 43 \\
\hline & $\mathrm{Cu}$ & $<5$ & 348 & 172 & 21 & $<5$ & $<5$ & 2 & 7 & 5 & 4 & 14 \\
\hline & $\mathrm{Ni}$ & 50 & 13 & 26 & 37 & 89 & 27 & 181 & 36 & 20 & 22 & 8 \\
\hline & v & 28 & 28 & 63 & 119 & 114 & 89 & 30 & 151 & 11 & 11 & 13 \\
\hline & $\mathrm{Hf}$ & 2,12 & 6,76 & 3,72 & 8,53 & 3,36 & 7,07 & - & - & - & - & - \\
\hline & Co & 11,2 & 7,9 & 7,7 & 13,5 & 20 & 9,2 & 16 & 19 & 5 & 7 & 4 \\
\hline \multirow{16}{*}{ 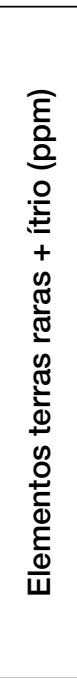 } & $Y$ & 19,13 & 22,8 & 20,03 & 19,81 & 10,8 & 21,28 & 5 & 7 & 12 & 5 & 8 \\
\hline & La & 24 & 58,1 & 64,7 & 178,5 & 8,7 & 32,9 & 18 & 25,1 & 36,6 & 6,3 & 20,2 \\
\hline & $\mathrm{Ce}$ & 38,9 & 123,4 & 129,6 & 341,8 & 9,7 & 70,7 & 30,5 & 40,9 & 66,8 & 18,9 & 43,9 \\
\hline & $\operatorname{Pr}$ & 4,81 & 15,29 & 15,02 & 38,4 & 1,55 & 9,95 & 3,08 & 4,1 & 6,47 & 3,18 & 5,81 \\
\hline & $\mathrm{Nd}$ & 18,3 & 58,7 & 55,2 & 132 & 7,6 & 44,9 & 12,5 & 17,3 & 24,8 & 16,8 & 25,6 \\
\hline & $\mathrm{Sm}$ & 3,2 & 10,6 & 9,4 & 19,3 & 1,8 & 9,5 & 2,1 & 3,8 & 3,6 & 3,5 & 4,7 \\
\hline & $\mathrm{Eu}$ & 0,68 & 2 & 1,31 & 3,87 & 0,46 & 1,88 & 0,58 & 1,17 & 0,8 & 0,49 & 1,04 \\
\hline & Gd & 3,1 & 8,11 & 6,63 & 10,11 & 2,21 & 7,83 & 2,07 & 4,39 & 3,44 & 2,96 & 4,3 \\
\hline & $\mathrm{Tb}$ & 0,47 & 0,95 & 0,81 & 1,15 & 0,33 & 0,95 & 0,22 & 0,56 & 0,35 & 0,31 & 0,46 \\
\hline & Dy & 2,78 & 4,67 & 4 & 4,83 & 1,85 & 4,79 & 1,67 & 3,76 & 2,3 & 1,91 & 2,96 \\
\hline & Ho & 0,54 & 0,8 & 0,66 & 0,79 & 0,37 & 0,74 & 0,23 & 0,65 & 0,34 & 0,26 & 0,47 \\
\hline & $\mathrm{Er}$ & 1,45 & 1,94 & 1,57 & 1,69 & 1,01 & 1,83 & 0,87 & 1,83 & 1,13 & 0,81 & 1,44 \\
\hline & $\mathrm{Tm}$ & 0,26 & 0,26 & 0,24 & 0,22 & 0,17 & 0,27 & $<0,05$ & 0,16 & 0,09 & $<0,05$ & 0,07 \\
\hline & $\mathrm{Yb}$ & 1,1 & 1,4 & 1,3 & 1,3 & 0,9 & 1,3 & 0,8 & 1,5 & 0,8 & 0,6 & 1,1 \\
\hline & Lu & 0,17 & 0,18 & 0,18 & 0,18 & 0,13 & 0,17 & $<0,05$ & 0,12 & $<0,05$ & 0,09 & $<0,05$ \\
\hline & $\Sigma E T R+Y$ & 118,89 & 309,2 & 310,65 & 753,95 & 47,58 & 208,99 & 77,62 & 112,34 & 159,52 & 61,11 & 120,05 \\
\hline \multirow{7}{*}{ 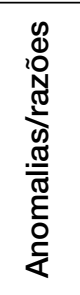 } & $\mathrm{Pr} / \mathrm{Yb}^{\star}{ }_{[\mathrm{SN}]}$ & 1,4 & 3,49 & 3,69 & 9,43 & 0,55 & 2,44 & 1,23 & 0,87 & 2,58 & 1,69 & 1,69 \\
\hline & $\mathrm{Ce} / \mathrm{Ce}^{\star}$ & 0,83 & 0,95 & 0,96 & 0,95 & 0,6 & 0,89 & 0,93 & 0,92 & 0,99 & 0,9 & 0,93 \\
\hline & $Y / Y^{*}$ & 1,24 & 0,94 & 0,98 & 0,8 & 1,04 & 0,89 & 0,63 & 0,36 & 1,07 & 0,55 & 0,54 \\
\hline & $\mathrm{Eu} / \mathrm{Eu}^{\star}$ & 1,89 & 2,13 & 0,78 & 3,3 & 1,8 & 2,07 & 2,42 & 2,3 & 2,01 & 1,43 & 2,09 \\
\hline & $\mathrm{Gd} / \mathrm{Gd}^{*}$ & 1,08 & 1,13 & 1,26 & 0,86 & 1,11 & 1,13 & 1,08 & 1,04 & 1,24 & 1,49 & 1,19 \\
\hline & $\mathrm{Y} / \mathrm{Ho}$ & 35,43 & 28,5 & 30,35 & 25,08 & 29,19 & 28,76 & 21,74 & 10,77 & 35,29 & 19,23 & 17,02 \\
\hline & $\mathrm{Eu} / \mathrm{Sm}$ & 0,21 & 0,19 & 0,14 & 0,2 & 0,26 & 0,2 & 0,28 & 0,31 & 0,22 & 0,14 & 0,22 \\
\hline
\end{tabular}


das amostras é marcada por discreta anomalia positiva de $\mathrm{Eu}\left(\mathrm{Eu} / \mathrm{Eu}^{*}=0,77-1,47\right)$ e negativa de $\mathrm{Ce}\left(\mathrm{Ce} / \mathrm{Ce}^{*}=0,44-\right.$ $1,02)$, bem como nos diopsiditos $\left(\mathrm{Ce} / \mathrm{Ce}^{*}=0,60-0,99\right)$. As anomalias de $\mathrm{Eu}$ oscilam entre positivas e negativas nos diopsiditos $\left(\mathrm{Eu} / \mathrm{Eu}^{*}=0,78-3,30\right)$, e o $\Sigma \mathrm{ETR}+\mathrm{Y}=$ 196 ppm apresenta proporções similares às dos mármores do Grupo 2. Em ambas as litologias, são observadas anomalias negativas de $\mathrm{Y}\left(\mathrm{Y} / \mathrm{Y}^{*}=0,36-1,24\right.$ nos diopsiditos e $0,26-1,50$ nas granulitizadas), sendo que a vasta maioria das amostras apresenta $\mathrm{Y} / \mathrm{Y}^{*}<1$. Anomalias significativas de Gd não são observadas, predominando valores em torno de 1 (Figuras 9A e 9B).

Tabela 4. Composição dos elementos maiores, traços, ETR + Y, anomalias e razões nas rochas calcissilicáticas granulitizadas.

\begin{tabular}{|c|c|c|c|c|c|c|c|c|c|c|c|c|c|c|c|}
\hline \multicolumn{2}{|c|}{ Amostra } & $\begin{array}{l}\text { TAJ- } \\
04 A\end{array}$ & $\begin{array}{l}\text { TAJ- } \\
26 \mathrm{~A}\end{array}$ & $\begin{array}{l}\text { TAJ- } \\
27 A\end{array}$ & $\begin{array}{c}\text { MM- } \\
01\end{array}$ & $\begin{array}{c}\text { MM- } \\
03\end{array}$ & $\begin{array}{c}\text { MM- } \\
04\end{array}$ & $\begin{array}{l}\text { MM- } \\
05\end{array}$ & $\begin{array}{c}\text { MM- } \\
07\end{array}$ & $\begin{array}{c}\text { MM- } \\
08\end{array}$ & $\begin{array}{c}\text { MM- } \\
17\end{array}$ & $\begin{array}{c}\text { MPD- } \\
03\end{array}$ & MI-03 & MI-05 & MI-06 \\
\hline \multirow{12}{*}{ 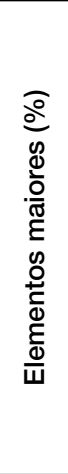 } & $\mathrm{SiO}_{2}$ & 50,54 & 38,74 & 61 & 74,69 & 48,67 & 48,03 & 43,9 & 46,76 & 51,45 & 54,13 & 53,5 & 49,65 & 48,23 & 48,28 \\
\hline & $\mathrm{TiO}_{2}$ & 1,91 & 0,07 & 1,4 & 0,19 & 1,41 & 1,98 & 2,44 & 1,88 & 2 & 1,79 & 1,04 & 1,71 & 2,17 & 2,23 \\
\hline & $\mathrm{Al}_{2} \mathrm{O}_{3}$ & 11,51 & 1,78 & 13,36 & 13,74 & 13,5 & 13,27 & 15,56 & 13,1 & 13,26 & 13,56 & 15,7 & 13,51 & 13,46 & 13,35 \\
\hline & $\mathrm{Fe}_{2} \mathrm{O}_{3}$ & 16,79 & 7,69 & 6,48 & 2,47 & 13,25 & 15,83 & 18,97 & 15,32 & 15,55 & 14,39 & 8,59 & 14,76 & 18,08 & 17,81 \\
\hline & $\mathrm{MnO}$ & 0,27 & 0,16 & 0,09 & $<0,01$ & 0,19 & 0,14 & 0,19 & 0,23 & 0,23 & 0,2 & 0,11 & 0,21 & 0,24 & 0,27 \\
\hline & $\mathrm{MgO}$ & 6,76 & 26,73 & 2,48 & 1,24 & 6,5 & 8,91 & 7,73 & 5,72 & 5,95 & 5,35 & 4,22 & 8,32 & 8,94 & 7,02 \\
\hline & $\mathrm{CaO}$ & 10,02 & 8,9 & 4,74 & 1,25 & 7,38 & 6,33 & 3,01 & 8,85 & 7,99 & 5,76 & 5,54 & 8,75 & 7,05 & 9,56 \\
\hline & $\mathrm{Na}_{2} \mathrm{O}$ & 2,18 & 0,15 & 5,46 & 4,24 & 4,74 & 2,96 & 2,39 & 3,43 & 3,54 & 4,67 & 4,24 & 3,05 & 2,57 & 2,74 \\
\hline & $\mathrm{K}_{2} \mathrm{O}$ & 0,92 & 0,45 & 3,6 & 3,9 & 0,54 & 1,13 & 2,08 & 0,48 & 0,53 & 0,55 & 5,22 & 0,85 & 0,97 & 0,5 \\
\hline & $\mathrm{P}_{2} \mathrm{O}_{5}$ & 0,08 & $<0,01$ & 0,71 & $<0,01$ & 0,05 & 0,1 & 0,1 & 0,1 & 0,12 & 0,14 & 1,2 & 0,22 & 0,13 & 0,13 \\
\hline & LOI & 0,63 & 10,66 & 0,37 & 0,23 & 0,79 & 0,32 & 1,53 & 0,36 & 0,86 & 0,16 & 0,71 & 0,16 & 0,2 & $<0,01$ \\
\hline & TOTAL & 101,61 & 95,33 & 99,69 & 101,95 & 97,02 & 99 & 97,9 & 96,23 & 101,48 & 100,7 & 100,07 & 101,19 & 102,04 & 101,9 \\
\hline \multirow{9}{*}{ 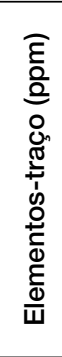 } & $\mathrm{Ba}$ & 293 & 228 & 3.779 & 60 & 444 & 3.171 & 1.234 & 49 & 35 & 202 & 876 & 600 & 356 & 92 \\
\hline & $\mathrm{Sr}$ & 269 & 45 & 1445 & 7 & 17 & 12 & 26 & 26 & 16 & 24 & 262 & 37 & 48 & 16 \\
\hline & $\mathrm{Zr}$ & 97 & 12 & 417 & $<1$ & 7 & $<1$ & $<1$ & 1 & $<1$ & $<1$ & 46 & 8 & 2 & 1 \\
\hline & $\mathrm{Zn}$ & 108 & 76 & 97 & 20 & 54 & 97 & 62 & 43 & 41 & 47 & 56 & 29 & 26 & 28 \\
\hline & $\mathrm{Cu}$ & 109 & 126 & 20 & 14 & 59 & 231 & 172 & 165 & 47 & 30 & 67 & 10 & 67 & 288 \\
\hline & $\mathrm{Ni}$ & 89 & 2.075 & 36 & 6 & 40 & 32 & 100 & 50 & 22 & 15 & 14 & 22 & 41 & 64 \\
\hline & v & 359 & 28 & 92 & 16 & 178 & 194 & 325 & 225 & 274 & 265 & 91 & 174 & 196 & 287 \\
\hline & $\mathrm{Hf}$ & 2,8 & 0,22 & 8,96 & - & - & - & - & - & - & - & - & - & - & - \\
\hline & Co & 65,9 & 133,5 & 14,6 & 5 & 26 & 30 & 59 & 28 & 22 & 20 & 17 & 20 & 26 & 33 \\
\hline \multirow{16}{*}{ 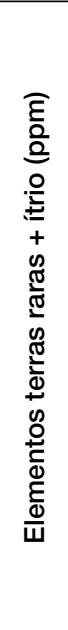 } & $Y$ & 23,94 & 1,74 & 21,23 & 4 & 8 & 11 & 10 & 8 & 9 & 9 & 22 & 12 & 10 & 8 \\
\hline & $\mathrm{La}$ & 13,7 & 8,2 & 211 & 62,2 & & & & 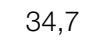 & & & & 3 & &, 5 \\
\hline & $\mathrm{Ce}$ & 23,7 & 4,7 & 402,1 & 92,7 & 23,5 & 45,2 & 71,4 & 67,6 & 36,8 & 50,3 & 353,4 & 69,3 & 45,2 & 23,6 \\
\hline & $\mathrm{Pr}$ & 3,35 & 0,47 & 42,24 & 7,76 & 2,78 & 5,44 & 8,03 & 7,28 & 4,47 & 5,47 & 36,3 & 7,76 & 5,06 & 3,28 \\
\hline & $\mathrm{Nd}$ & 16,9 & 1,4 & 147,1 & 26,3 & 13,7 & 26,2 & 35,1 & 30,4 & 21,9 & 24,5 & 141,2 & 33,4 & 23,1 & 17,7 \\
\hline & $\mathrm{Sm}$ & 4,5 & 0,3 & 19,3 & 3,1 & 3,6 & 6 & 7,4 & 5,5 & 5,5 & 5,1 & 21,3 & 6,5 & 5,1 & 5,1 \\
\hline & $\mathrm{Eu}$ & 1,5 & 0,05 & 4,32 & 0,97 & 1,21 & 1,81 & 1,45 & 1,61 & 1,5 & 1,65 & 5,72 & 1, & & 1,5 \\
\hline & Gd & 5,13 & 0,31 & 10,95 & 2,33 & 4,16 & 6,68 & 7,98 & 5,56 & 6,14 & 5,42 & 15,99 & 6,45 & 5,25 & 5,62 \\
\hline & $\mathrm{Tb}$ & 0,8 & 0,05 & 1,19 & 0,12 & 0,53 & 0,88 & 1,1 & 0,75 & 0,83 & 0,71 & 1,58 & 0,86 & 0,68 & 0,81 \\
\hline & Dy & 4,82 & 0,26 & 4,8 & 0,69 & 3,71 & 5,68 & 7,12 & 4,45 & 5,58 & 4,77 & 6,82 & 5,39 & 4,43 & 5,19 \\
\hline & Ho & 0,91 & 0,05 & 0,8 & 0,05 & 0,64 & 1,01 & 1,28 & 0,77 & 0,99 & 0,81 & 1,03 & 0,94 & 75 & 0,88 \\
\hline & Er & 2,33 & 0,17 & 1,86 & 0,19 & 1,9 & 3,11 & 3,89 & 2,24 & 3,06 & 2,44 & 2,77 & 2,81 & 2,22 & 2,58 \\
\hline & $\mathrm{Tm}$ & 0,37 & 0,05 & 0,28 & $<0,05$ & 0,15 & 0,29 & 0,43 & 0,23 & 0,31 & 0,23 & 0,23 & 0,29 & 0,2 & 0,26 \\
\hline & $\mathrm{Yb}$ & 2 & 0,1 & 1,3 & 0,1 & 1,5 & 2,6 & 3,5 & 1,9 & 2,6 & 2,1 & 2 & 2,5 & 1,8 & 2,2 \\
\hline & Lu & 0,28 & 0,05 & 0,19 & $<0,05$ & 0,12 & 0,26 & 0,35 & 0,17 & 0,28 & 0,22 & 0,18 & 0,25 & 0,16 & 0,21 \\
\hline & $\Sigma \mathrm{ETR}+\mathrm{Y}$ & 104,23 & 17,9 & 869,46 & 200,51 & 78,1 & 139,76 & 194,13 & 171,16 & 116,35 & 144,32 & 801,32 & 181,68 & 129,42 & 86,43 \\
\hline \multirow{7}{*}{ 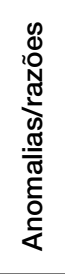 } & $\mathrm{Pr} / \mathrm{Yb}^{*}{ }_{[\mathrm{SN}]}$ & 0,53 & 1,5 & 10,38 & 24,78 & 0,59 & 0,67 & 0,73 & 1,22 & 0,55 & 0,83 & 5,8 & 0,99 & 0,9 & 0,48 \\
\hline & $\mathrm{Ce} / \mathrm{Ce}^{*}$ & 0,81 & 0,44 & 0,98 & 0,93 & 0,92 & 0,92 & 0,98 & 0,98 & 0,96 & 0,87 & 0,98 & 1,02 & 0,95 & 0,96 \\
\hline & $Y / Y^{*}$ & 0,91 & 1,22 & 0,86 & 1,5 & 0,41 & 0,36 & 0,26 & 0,34 & 0,3 & 0,36 & 0,65 & 0,42 & 0,43 & 0,3 \\
\hline & $\mathrm{Eu} / \mathrm{Eu}^{*}$ & 1,45 & 0,77 & 1,37 & 1,7 & 1,45 & 1,33 & 0,88 & 1,37 & 1,28 & 1,47 & 1,46 & 1,33 & 1,51 & 1,31 \\
\hline & $\mathrm{Gd} / \mathrm{Gd}^{*}$ & 0,91 & 1,2 & 0,85 & 0,95 & 0,99 & 1,02 & 1,24 & 0,97 & 1,04 & 0,95 & 0,94 & 0,99 & 0,93 & 0,99 \\
\hline & Y/Ho & 26,31 & 34,8 & 26,54 & 80 & 12,5 & 10,89 & 7,81 & 10,39 & 9,09 & 11,11 & 21,36 & 12,77 & 13,33 & 9,09 \\
\hline & $\mathrm{Eu} / \mathrm{Sm}$ & 0,33 & 0,17 & 0,22 & 0,31 & 0,34 & 0,3 & 0,2 & 0,29 & 0,29 & 0,32 & 0,27 & 0,28 & 0,33 & 0,29 \\
\hline
\end{tabular}




\section{DISCUSSÃO}

\section{Interpretação das condições paleoambientais}

Devido ao grau deformacional e de metamorfismo que obliteram por completo estruturas primárias, torna-se impossível a reconstituição completa da sucessão metassedimentar do Vale do Jacuri. Entretanto, algumas correlações entre elementos e padrões geoquímicos primordiais preservados permitem dissertar acerca de condições paleoambientais que estiveram envolvidas na gênese das litologias caracterizadas, fazendo uso, sobretudo, das assinaturas de ETR + Y.

O modelo sugerido por Nelson et al. (2010) para a configuração dos mares proterozoicos descreve o seguinte cenário: existência de oceanos estratificados em zonas óxicas, subóxicas e anóxicas, associados à produção de oxigênio fotossintético em uma zona próxima à costa (águas rasas). Kazakov (1937) propôs um modelo de plataforma extensamente oxigenada para o Fanerozoico, dominada pela existência de correntes de ressurgência.

De acordo com McLennan (1989), as concentrações de $\mathrm{ETR}+\mathrm{Y}$ em rochas sedimentares podem ser controladas, entre outros fatores, pelas fases minerais presentes na rocha. Contribuição de quantidades diminutas de material clástico, ou seja, de input terrígeno, pode resultar em aumento dos teores e das correlações entre elementos litófilos, como o Hf e o Zr, aumento da concentração de ETR + Y e achatamento dos seus padrões de distribuição em rochas marinhas. Teores mais elevados de $\mathrm{Al}_{2} \mathrm{O}_{3}$ são outros indicadores de contaminação detrítica (Corkeron et al., 2012).

Os diopsiditos e os granulitos calcissilicáticos demonstraram correlação positiva entre $\mathrm{Zr}$ e Hf, sugerindo contribuição
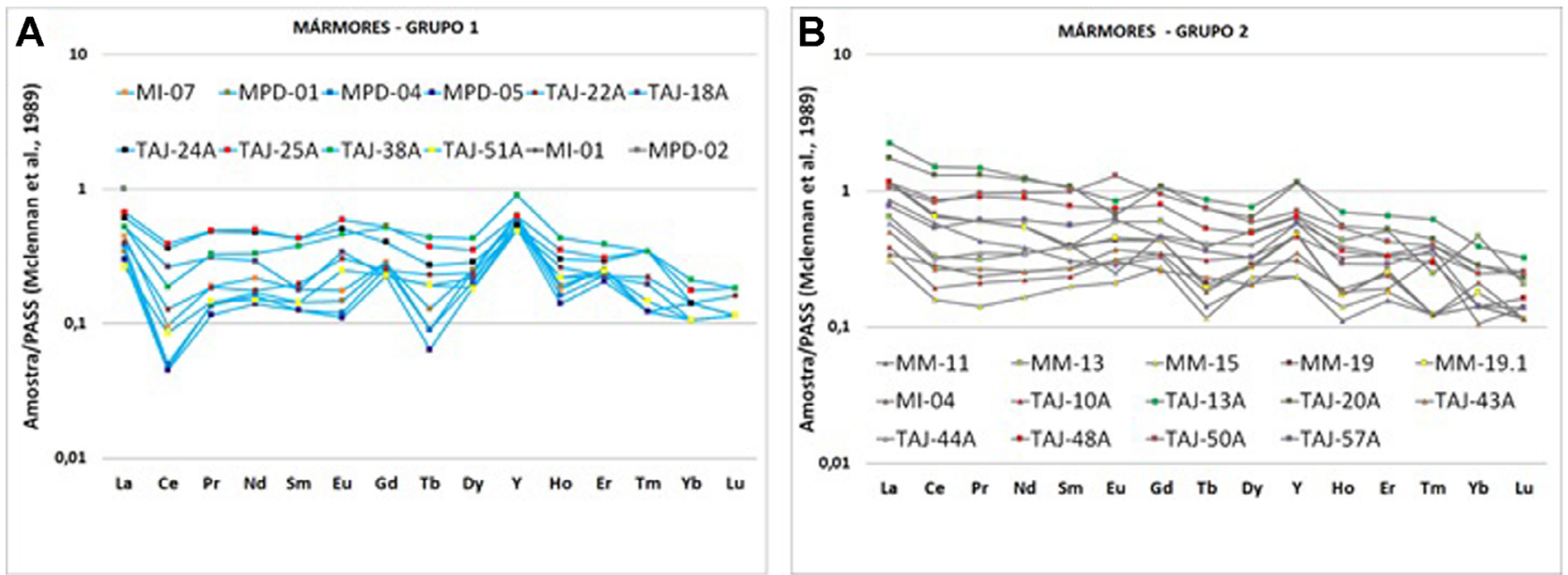

Figura 8. Padrão de ETR+Y (A) nos mármores do Grupo 1 e (B) nos mármores do Grupo 2 do Vale do Jacurici, normalizados para o PAAS (McLennan et al., 1989).
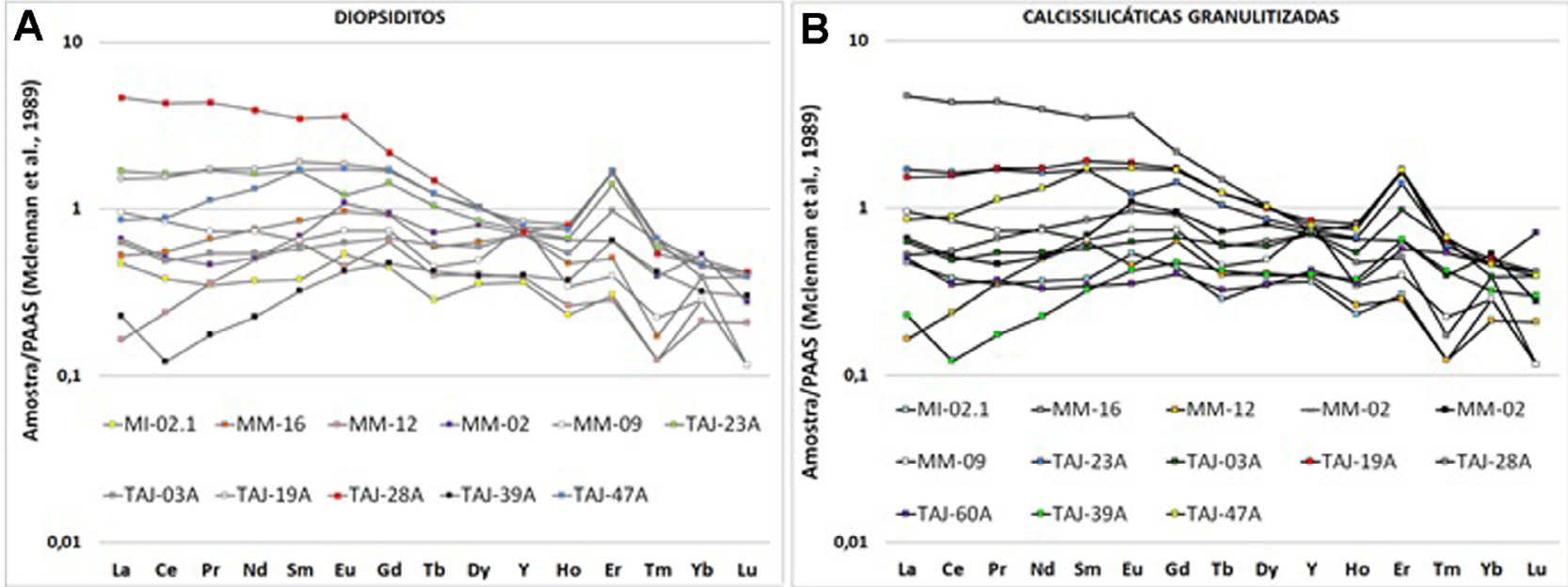

Figura 9. Diagrama spider dos $E T R+Y(A)$ nos diopsiditos e $(B)$ nas rochas calcissilicáticas granulitizadas do Vale do Jacurici, normalizados para o PAAS (McLennan et al., 1989). 
detrítica de material crustal nas rochas mais ricas nesses elementos (Figura 10A). Nos mármores, apesar de observável, essa correlação é menos evidente e descontínua, sobretudo nos mármores do Grupo 1, refletindo a predominância, nessa unidade, da sedimentação química em ambiente marinho longe da zona de input continental.

Em paralelo, são observados maiores valores de elementos que sugerem contaminação clástica, como $\mathrm{Fe}_{2} \mathrm{O}_{3}$, $\mathrm{Al}_{2} \mathrm{O}_{3}, \mathrm{~K}_{2} \mathrm{O}, \mathrm{MnO}$ e $\mathrm{TiO}_{2}$, bem como $\mathrm{V}, \mathrm{Co}, \mathrm{Cu} \mathrm{Zn}$ e Zr, e, consequentemente, minerais que contenham esses elementos, como granada, biotita e muscovita nos mármores do Grupo 2 e nas rochas calcissilicáticas. O aumento do valor de $\mathrm{V}$ dos mármores para as calcissilicáticas pode ocorrer, pois, durante os processos exógenos, esse elemento é intensamente incorporado aos minerais argilosos. $\mathrm{O} \mathrm{V}^{5+}$ se mobiliza com facilidade e, se existirem metais pesados nas águas subterrâneas e nas soluções da meteorização, podem surgir maiores concentrações locais de vanadatos de $\mathrm{Cu}, \mathrm{Pb}, \mathrm{Zn}$ e U, em particular na zona de oxidação e na presença de margas e dolomitos, que originam um $\mathrm{pH}$ adequado para precipitação dos vanadatos (Fonseca, 2013). As demais litologias também exibem razões $\mathrm{Pr} / \mathrm{Yb}_{[\mathrm{SN}]}$ maiores e enriquecimento maior de $\Sigma \mathrm{ETR}+\mathrm{Y}$ no geral, estando próximas ou acima de 1 dos valores do PASS, que, por sua vez, representa valores crustais.

\section{Anomalias de Ce, Eu e Gd}

As anomalias de Ce representam ferramenta geoquímica fundamental em estudos aplicados a sedimentos marinhos proterozoicos (Taylor e McLennan, 1985). Devido a sua sensibilidade ao estado de redox do ambiente, o Ce representa o traçador principal para a evolução oceânica-atmosférica ao longo do tempo geológico (Towe, 1991; Lawrence e Kamber, 2006). Nesse contexto, torna-se essencial evitar anomalias que possam ser mascaradas pela mobilidade do lântanio (La), que se torna superabundante quando submetido a processos pós-deposicionais e na presença de outros minerais de origem detrítica. A abordagem descrita por Bau e Dulski (1996) foi adotada para discriminar amostras com anomalias negativas verdadeiras de $\mathrm{Ce}$ e as com anomalias positivas de La, em que utiliza-se a relação Ce/Ce* versus $\mathrm{Pr} / \mathrm{Pr}^{*}$ com o normalizador PASS (Figura 10B).

Os mármores do Grupo 1 apresentam anomalias negativas verdadeiras de $\mathrm{Ce}(\mathrm{Pr} / \mathrm{Pr} *>1)$. Já os mármores do Grupo 2 e as rochas calcissilicáticas não apresentam anomalias relevantes de $\mathrm{Ce}$, indicando a influência de enriquecimento de La, citada por Bau e Dulski (1996) (Figura 10B).

Tendo em vista esses resultados, os mármores do Grupo 1 foram, portanto, utilizados com maior confiabilidade no estudo de assinaturas de ETR + Y como meio de fornecer informações sobre as condições paleoceanográficas da bacia.

Como o Ce apresenta-se em dois estados de oxidação estáveis $\left(\mathrm{Ce}^{+3} \mathrm{e} \mathrm{Ce}^{+4}\right)$, característica exclusiva dentre os ETRs, torna-se intensamente sujeito a anomalias. Em águas rasas, nas quais há abundância de oxigênio, $\mathrm{o} \mathrm{Ce}^{+3}$ oxida para $\mathrm{o}$ $\mathrm{Ce}^{+4}$, sendo facilmente incorporado em partículas sedimentares constituídas por Fe-Mn, muitas das quais têm anomalias positivas, empobrecendo a água do mar nesse elemento (Piper, 1974; Elderfield et al., 1981).
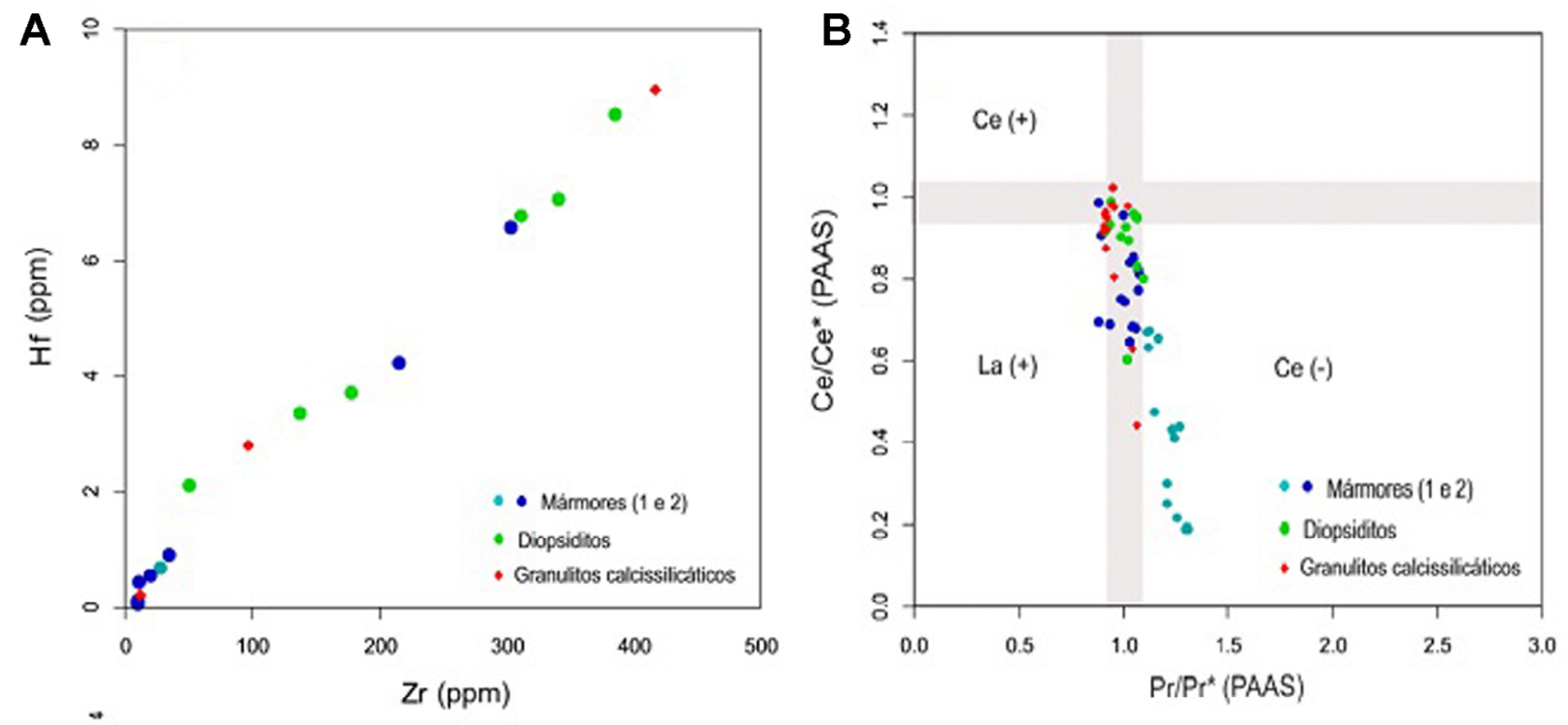

Figura 10. (A) Relação binária entre os elementos litófilos nos mármores e nas rochas calcissilicáticas; (B) diagrama (Ce/ $\mathrm{Ce}^{\star}$ ) versus ( $\left.\mathrm{Pr} / \mathrm{Pr}^{*}\right)$ normalizados ao PAAS, indicando campos de anomalias negativas e positivas verdadeiras em Ce, e anomalias positivas de La de todas as amostras. 
O estudo dessas anomalias pode fornecer, portanto, informações sobre a profundidade relativa da gênese dessas rochas, bem como a proximidade com fontes hidrotermais de alta temperatura. Anomalias negativas de $\mathrm{Ce}$ em relação ao PAAS são observadas na água do mar em ambientes oxigenados (rasos), enquanto as positivas são indicadores de ambientes redutores, bem como águas lacustres alcalinas ricos em carbonato aeróbico (Moller e Bau, 1993) ou input de sedimentos costeiros redutores (De Baar et al., 1983).

Os mármores amostrados do Grupo 1 apresentam anomalias negativas acentuadas de $\mathrm{Ce}$, evidenciando condições paleoambientais óxicas durante sua gênese, o que seria possível em profundidades rasas, tendo em vista os modelos assumidos para plataformas pré-cambrianas. Já os mármores do Grupo 2 e as rochas calcissilicáticas não apresentam anomalias negativas tão acentuadas de Ce. As indicações de input terrígeno possivelmente refletiram na diminuição desses padrões.

Um dos principais efeitos na mobilidade dos ETR são as elevadas anomalias positivas de Eu em litofácies que hospedam minerais oriundos da ação de fluidos metassomáticos (Grauch, 1989; Bau, 1993). Bolhar e Van Kranendonk (2007) situaram anomalias positivas de Eu como reflexo do input de fluidos hidrotermais provenientes de cadeias meso-oceânicas (MOR), processo muito mais intenso no Arqueano. Nesse contexto, a presença de magnitudes variáveis de anomalias positivas de Eu nas rochas estudadas pode ser reflexo das assinaturas das águas dos mares arqueanos residuais nos oceanos paleo-mesoproterozoicos, bem como da contribuição de sedimentos e rochas vulcânicas provenientes de cadeias meso-oceânicas ou da influência de fluidos magmáticos tardios.

As composições atuais da água do mar são caracterizadas por anomalias positivas de $\mathrm{Gd}$, observadas de forma notória em uma porção das amostras dos mármores do Grupo 1. Estas são atribuídas por Bau (1999) a maior estabilidade desse elemento, em relação aos vizinhos, em ser incorporado a complexos em águas marinhas. Segundo Lee e Byrne (1993), o enriquecimento de Gd na água do mar ocorre, principalmente, devido à baixa estabilidade do $\mathrm{Gd}$ na complexação de partículas. Dentre os fatores que levam ao seu fracionamento preferencial entre os ETR + Y estão condições biogênicas, $\mathrm{pH}$, temperatura e pressão. É possível observar que a porção das amostras do Grupo 1 que não apresentam anomalias de Gd exibe nítidas anomalias positivas de Eu, bem como maior concentração total de ETR + $\mathrm{Y}$, evidenciando que ocorrem, dentro dessa unidade, graus diferentes de preservação de assinaturas marinhas.

\section{Anomalias de Y e correlações Y/Ho}

O ítrio (Y) e o hólmio (Ho) são elementos com comportamento geoquímico idêntico, devido à similaridade de suas cargas e seus raios iônicos. Em estudos geoquímicos de formações ferríferas, estes pares são comumente assumidos como exclusivamente ligados a componentes detríticos e, portanto, são, muitas vezes, utilizados como parâmetro de contaminação dos sedimentos químicos com relação à presença de detritos na bacia (Bau, 1993; Bolhar et al., 2004). Sabe-se ainda que o Ho é eliminado por meio de partículas em suspensão no sistema marinho duas vezes mais rápido do que $\mathrm{Y}$, gerando anomalias positivas de $\mathrm{Y}$ características em rochas formadas em ambientes marinhos abertos sem input siliciclástico (Bau et al., 1997; De Baar et al., 1985; Nozaki et al., 1997), situação bem marcada nos mármores do Grupo 1.

Considera-se o valor de referência para água do mar de $\mathrm{Y} / \mathrm{Ho}=60-90$ (Bau, 1999). Ainda, Johannesson et al. (2006) compilaram valores Y/Ho entre 92.2-168 ambientes oceânicos em diversos lugares do mundo. Os valores para águas continentais situam-se mais próximos dos valores crustais entre 26-27, referentes ao folhelho PAAS. As razões encontradas podem indicar mistura em maior ou menor quantidade de água doce no período de deposição.

Os mármores estão inseridos, próximos ao campo de assinatura da água do mar, com valores Y/Ho (Grupo 1 $=47.13-145.29$ e Grupo $2=35.85-76.88)$, muito aproximados do valor referência para água do $\operatorname{mar}(\mathrm{Y} / \mathrm{Ho}=$ 60-168), sobretudo os do Grupo 1. Essa relação nos diopsiditos $(\mathrm{Y} / \mathrm{Ho}=10.77-35.43)$ e granulitos calcissilicáticos $(\mathrm{Y} / \mathrm{Ho}=7.81-26.54)$ é correlacionável aos valores crustais $(\mathrm{Y} / \mathrm{Ho}=26-27)$.

As amostras estudadas com razões $\mathrm{Y} / \mathrm{Ho}$ mais baixas, sobretudo os granulitos calcissilicáticos, não apresentam correlações entre ETRs leves e pesados, representados pela razão $\mathrm{Pr} / \mathrm{Yb}_{[\mathrm{SN}]}$, e foram plotadas dentro do campo da composição shale determinada por Planavsky et al. (2010), evidenciando forte assinatura de input terrígeno (Figura 11A). Para os mármores do Grupo 1, as amostras exibem relação linear negativa. Aplicando-se a correlação às anomalias de Ce (Figura 11B), observa-se comportamento linear negativo ainda mais acentuado, com influências também mais evidentes no Grupo 1, evidenciando que o enriquecimento em ETP e o empobrecimento em Ce são favorecidos em ambiente marinho, principalmente onde a contaminação detrítica é ausente ou mais restrita.

Considerando-se ainda esse contexto, Alexander et al. (2008) e Bau e Dulski (1996) fizeram uso da relação Y/Ho versus $\mathrm{Eu} / \mathrm{Sm}$ para identificar assinaturas marinhas e avaliar a influência de fluidos de baixa e alta temperatura (Figura 12). A correlação obtida para todas as litologias não indica participação de fluidos hidrotermais de alta temperatura, sugerindo posição distal das fontes hidrotermais na época da sua deposição, bem como preservação de suas assinaturas geoquímicas mesmo após a influência de fluidos hidrotermais de baixa temperatura, depois de sua consolidação. 
As correlações geoquímicas apresentadas para os mármores e as rochas calcissilicáticas do Vale do Jacurici indicam a ocorrência de mistura expressiva de períodos de deposição siliciclástica e períodos de sedimentação química em um mesmo local da bacia, com contribuição de material carbonático e pelítico em ambiente marinho plataformal com diversos graus de contribuição de fluidos continentais, possivelmente de ambiente estuarino. Os padrões marinhos bem definidos nos mármores do Grupo 1 indicam condições óxicas envolvidas durante sua precipitação, restritas à plataforma interna (rasa) nos mares proterozoicos.

\section{Considerações sobre as anomalias de $\mathrm{P}_{2} \mathrm{O}_{5}$}

Os maiores depósitos de fosforito são registrados no Fanerozoico e em duas Eras do Proterozoico: Neoproterozoico e Paleoproterozoico, não sendo conhecidos depósitos importantes no Mesoproterozoico e no Arqueano. Esses períodos estão diretamente relacionados com eventos glaciais de escala mundial e de oxigenação da atmosfera terrestre, pois representam condições favoráveis à implantação de sistemas fosfogenéticos, conforme citado por Cook e Shergold (1984). Além da alta produção e concentração de $\mathrm{P}$, as mudanças nas condições climáticas em períodos pós-glaciais podem levar a grande aumento na disponibilidade de nutrientes, como o P solúvel, em águas subóxicas a anóxicas (Shields et al., 2000), isso porque a exposição de grandes áreas continentais que antes estavam cobertas por gelo ficam, com a deglaciação, sujeitas à erosão, podendo-se notar aumento da taxa de lixiviação de fósforo a ser transportado para o oceano (Papineau, 2010; Pufahl e Hiatt, 2012).

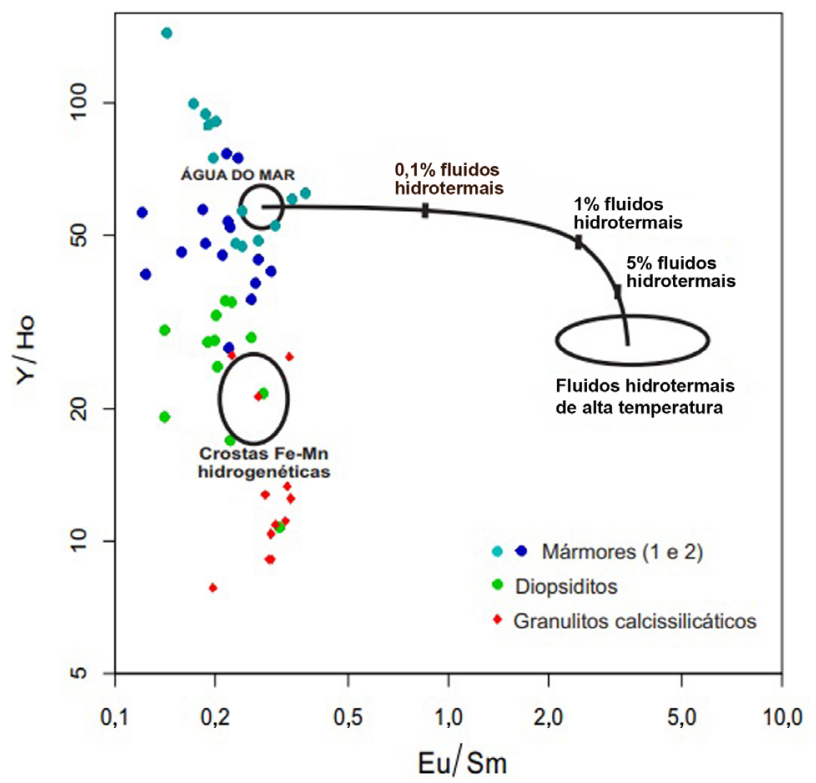

Fonte: Alexander et al. (2008).

Figura 12. Relação Eu/Sm versus $\mathrm{Y} / \mathrm{Ho}$ para todas as amostras supracrustais. A curva descendente indica campos de contribuição de fluidos de alta temperatura (> $350^{\circ} \mathrm{C}$ ), o círculo superior o campo que mais se aproximam de água oceânicas mais rasas $(<500 \mathrm{~m})$ e a elipse inferior, maior contribuição de crostas de Fe-Mn hidrotermais.
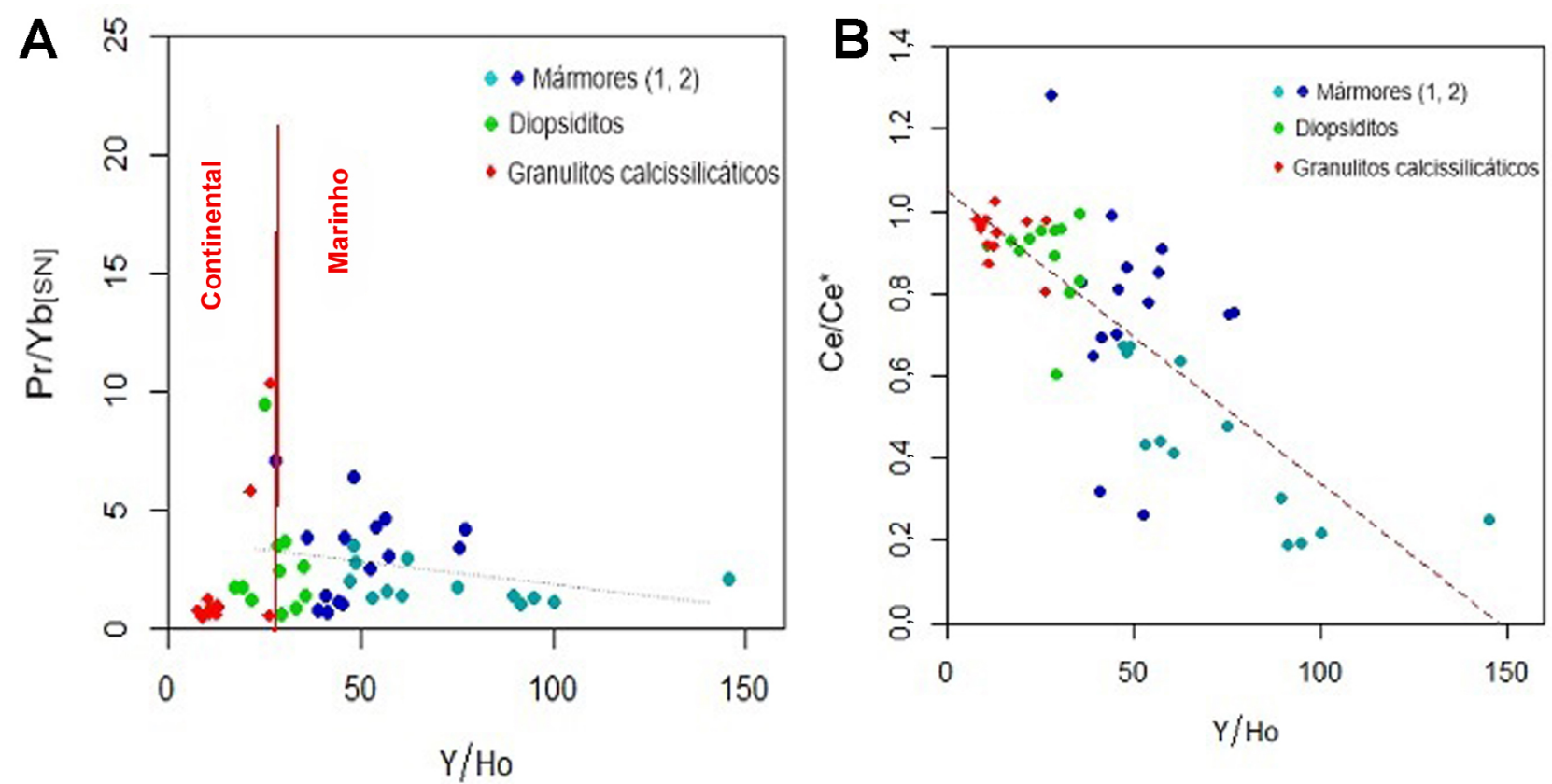

Figura 11. Relação binária $Y /$ Ho nos mármores e rochas calcissilicáticas do Vale do Jacurici em relação $(A)$ à razão entre ETRL e ETRP $\left(\operatorname{Pr} / \mathrm{Yb}_{[S N]}\right)$ e $(\mathrm{B})$ às anomalias de $\mathrm{Ce}$, segundo gráfico de Planavsky et al. (2010), exibindo trend linear descrescente. 
Tendo em vista esse cenário, o evento fosfogenético mais antigo ocorreu em sequência ao GOE e à pós-glaciação Huroniana, no Paleoproterozoico. Os depósitos de rochas fosfáticas do Paleoproterozoico, em sua vasta maioria, encontram-se dobrados, falhados e, frequentemente, metamorfizados, assim como as rochas carbonáticas e calcissilicáticas do Vale do Jacurici. Entretanto, a maioria deles consiste em depósitos econômicos, como os de Sinpkhup, Singpung e Yongby, na Coreia do Norte, com reservas estimadas em $100 \mathrm{Mt}$ de $\mathrm{P}_{2} \mathrm{O}_{5}$; o Supergrupo Aravalli, na Formação Jhamarkotra, Índia, com reservas estimadas $>65$ Mt de $\mathrm{P}_{2} \mathrm{O}_{5}$; e os depósitos na Rússia, com reservas estimadas em 50 Mt (Papineau, 2010).

Ainda que não haja dados disponíveis de datação absoluta das rochas estudadas, atualmente, considera-se a idade mínima de deposição como $2084 \pm 9 \mathrm{Ma}$, em referência à do Sienito de Itiúba, e de $2085 \pm 5 \mathrm{Ma}$, idade do Complexo Máfico-ultramáfico Vale do Jacurici, ambos intrusivos (Oliveira et al., 2004). Maheshwari et al. (2010) obtiveram dados de $\delta^{13} \mathrm{C}$ em mármores, que variam de $+2.2 \mathrm{a}+6.9 \%$, sendo correlacionados com os valores das rochas carbonáticas do Supergrupo Aravalli, na Índia $\left(\delta^{13} \mathrm{C}=+5.4 \mathrm{a}+11.2\right)$. A idade obtida em dolomitos da Fm. Jhamarkotra é de 1921 $\pm 67 \mathrm{Ma}$ (Sarangi et al., 2006), enquanto a idade mínima da sequência supracrustal é indicada em 2075-2150 Ma (Pb$\mathrm{Pb}$ ), obtida em galenas intercaladas com rochas vulcânicas basais (Deb e Thorpe, 2004).

A precipitação do $\mathrm{P}$ em uma bacia com baixa disponibilidade de oxigênio, que configura uma bacia paleoproterozoica, ocorreria no limite entre zonas anóxicas e subóxicas, na plataforma carbonática mais distal (com maior contribuição de bactéricas anaeróbicas em zonas anóxicas para redução do $\mathrm{PO}_{4}$ ), conforme descrito por Nelson et al. (2010), configurando um sistema fosfogenético. Conteúdos consideráveis de $\mathrm{PO}_{4}{ }^{2-}$ são fornecidos à plataforma continental juntamente com o Fe, complexados em oxi-hidróxidos de $\mathrm{Fe}$. Ao atingirem a região limítrofe entre zona subóxica a anóxica, esses complexos sofrem redução pela ação de micro-organismos, liberando o $\mathrm{P}$, o qual combinaria com o $\mathrm{F}$ e o $\mathrm{CO}_{2}$ da água marinha intersticial, dando origem ao carbonato-fluorapatita ou à francolita, principal mineral dos fosforitos marinhos, em um processo denominado de bombeamento Fe-redox.

Esse processo é marcado na sucessão estudada pelos maiores teores de $\mathrm{P}_{2} \mathrm{O}_{5}$, ainda que baixos do ponto de vista econômico, na interfácie entre mármores e diopsiditos, conforme exibe a relação Y/Ho versus $\mathrm{P}_{2} \mathrm{O}_{5}$ (Figura 13A). Neste estudo, foram utilizadas apenas amostras que apresentaram teores $>1 \%$, no geral, obtidas em furos realizados na região de Ipueira.

A relação $\mathrm{Y} / \mathrm{Ho}$ versus $\mathrm{Al}_{2} \mathrm{O}_{3}$ evidencia que interações que ocorrem entre a zona limítrofe de contibuição terrígena e marinha permanecem preservadas nas amostras estudadas, estando em torno da razão $\mathrm{Y} / \mathrm{Ho}=30$ (Figura 13B). As anomalias de fosfato obtidas no Vale do Jacurici apresentam, portanto, nítido controle sedimentar-estratigráfico preservado.

Análises de DRX indicam a presença de fluorapatita (Ca.F.Mn.O.P) nos mármores, bem como as análises de
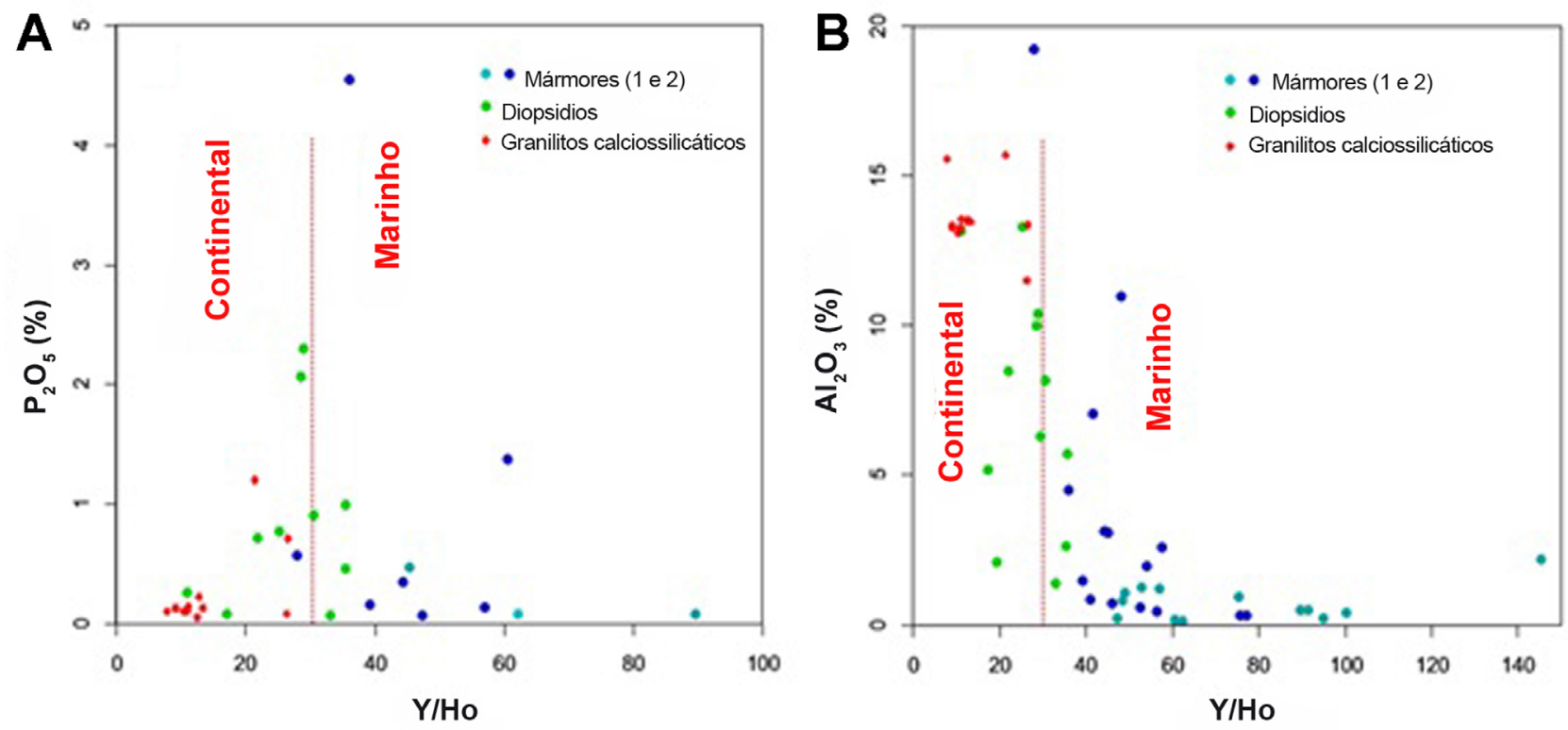

Fonte: Ribeiro (2016).

Figura 13. Diagramas de variação $(A) \mathrm{Y} / \mathrm{Ho} \times \mathrm{P}_{2} \mathrm{O}_{5} ;(\mathrm{B}) \mathrm{Y} / \mathrm{Ho} \times \mathrm{Al}_{2} \mathrm{O}_{3}$. A linha vermelha marca uma possível transição das amostras supracrustais estudadas, considerando as zonas de maior contribuição de águas continentais $(\mathrm{Y} / \mathrm{Ho}<30)$ e de águas marinhas (Y/Ho > 30 ppm), segundo Alexander et al. (2008). 
MEV em apatitas presentes nos diopsiditos indicaram composições correlacionáveis à da francolita, com teores, ainda que baixos, de F e Na. Ainda, Sanches (1997) demonstra que a composição da francolita desenvolve progressivamente características de fluorapatita durante intemperismo. Uma das primeiras modificações verificadas no carbonato fluorapatita, com a atuação de processos intempéricos, é a descarbonatação com a perda do $\mathrm{CO}_{3}^{-2}$ da estrutura, acompanhada da lixiviação de outros elementos. Esses processos são ainda mais intensos durante o metamorfismo. Tendo em vista esses dados, sugere-se que as apatitas estudadas apresentam gênese sedimentar, geradas em ambiente favorável à sua concentração por processos primários, não sendo descartada a possibilidade da influência da sua remobilização hidrotermal e recristalização.

\section{CONCLUSÕES}

Os padrões de ETR + Y e elementos-traço, em conjunto com as características petrográficas, mineralógicas e de distribuição dos elementos maiores analisados nas amostras disponíveis da sucessão carbonática e calcissilicática do Vale do Jacurici, marcam nitidamente a natureza sedimentar marinha dessas rochas.

A ocorrência de anomalias negativas de Ce e positivas de $\mathrm{Ye} \mathrm{Gd}$, as relações $\mathrm{Y} / \mathrm{Ho}$ em torno dos valores marinhos, bem como os baixos teores de $\mathrm{SiO}_{2}, \mathrm{Fe}_{2} \mathrm{O}_{3}, \mathrm{MnO}, \mathrm{Al}_{2} \mathrm{O}_{3}, \mathrm{TiO}_{2}$ e metais traços $(\mathrm{V}, \mathrm{Co}, \mathrm{Cu}, \mathrm{Zn})$ nos mármores do Grupo 1 , em relação aos mármores do Grupo 2, diopsiditos e rochas calcissilicáticas granulitizadas, a ocorrência de anomalias indica ambiente marinho raso envolvido na gênese dessas rochas. O teor de oxigênio disponível na bacia era alto o suficiente para a estabilização significativa de compostos de $\mathrm{Ce}^{+4} \mathrm{e}$, consequentemente, para a precipitação de carbonato e o favorecimento da precipitação de fosfato.

Quantidades variadas de input terrígeno na bacia resultaram em aumento da relação $\mathrm{Pr} / \mathrm{Yb}{ }_{[\mathrm{SN}]}$, achatamento dos padrões de ETR + Y ilustrado na ausência de anomalias expressivas de $\mathrm{Ce}, \mathrm{Y}$ e $\mathrm{Gd}$, bem como seu enriquecimento total $(\Sigma \mathrm{ETR}+\mathrm{Y})$ nos diopsiditos e granulitos calcissilicáticos. Essa influência também é evidente nas relações positivas $\mathrm{Zr}$ versus $\mathrm{Hf}$, nos valores $\mathrm{Y} / \mathrm{Ho}$ próximos aos crustais, nos teores mais elevados dos elementos maiores e metais traços descritos, bem como na presença de minerais que contêm estes elementos.

A presença de magnitudes variáveis de anomalias positivas de Eu nas rochas estudadas pode refletir das assinaturas das águas dos mares Arqueanos residuais nos oceanos Paleo-Mesoproterozoicos, bem como da contribuição de sedimentos e rochas vulcânicas proveniente de cadeias meso-oceânicas ou fluidos magmáticos tardios.
As relações geoquímicas obtidas indicam mistura expressiva de períodos de deposição siliciclástica e períodos de sedimentação química em um mesmo local da bacia, com contribuição de material carbonático e pelítico em ambiente marinho plataformal com diversos graus de contribuição de fluidos continentais, possivelmente de ambiente estuarino.

Apesar de as anomalias de $\mathrm{P}_{2} \mathrm{O}_{5}(1,38,2,07,2,3$ e 4,56\%) obtidas nas amostras estudadas de diopsiditos e mármores (Grupos 1 e 2) não representarem valores econômicos, elas são relevantes do ponto de vista científico. A constatação da preservação do controle estratigráfico nos eventos fosfogenêticos marinhos em ambientes intensamente metamorfizados possibilita que este estudo tenha aplicabilidade como guia para a prospecção mineral em bacias paleoproterozoicas, cuja favorabilidade para ocorrência de depósitos de fosfato econômicos é amplamente conhecida.

\section{AGRADECIMENTOS}

Os autores agradecem ao CNPQ, ao Programa de PósGraduação em Geologia da UFBA, à CIA Ferro Ligas da Bahia (FERBASA) e à Companhia Baiana de Pesquisa Mineral (CBPM), pelo apoio durante o desenvolvimento do trabalho, idealizado e executado pelo Grupo de Metalogênese (UFBA).

\section{REFERÊNCIAS}

Alexander, B. W., Bau, M., Andersson, P., Dulski, P. (2008). Continentally-derived solutes in shallow Archean seawater: rare earth element and $\mathrm{Nd}$ isotope evidence in iron formation from the $2.9 \mathrm{Ga}$ Pongola Supergroup, South Africa. Geochimica et Cosmochimica Acta, 72(2), 378-394. https://doi.org/10.1016/j.gca.2007.10.028

Almeida, F. F. M. (1967). Origem e evolução da plataforma brasileira. DNPM-DGM Boletim, 241, 36 p.

Almeida, F. F. M. (1977). O Cráton do São Francisco. Revista Brasileira de Geociências, 7(4), 349-364.

Barbosa J. S. F., Dominguez J. M. L. (1996). Texto Explicativo para o Mapa Geológico da Bahia ao Milionésimo. Salvador: SICM/SGM. Edição Especial.

Barbosa, J. S. F., Mascarenhas, J. F., Corrêa-Gomes, L. C., Dominguez, J. M. L., Souza, J. S. (2012). Geologia da Bahia: Pesquisa e Atualização. Salvador: CBPM-Companhia Baiana de Pesquisa Mineral. 
Barbosa, J. S. F., Sabaté, P., Marinho, M. M. (2003). O Cráton do São Francisco na Bahia: uma síntese. Revista Brasileira de Geociências, 33(1 Supl.), 3-6. https://doi. org/10.25249/0375-7536.200333S10306

Bau, M. (1993). Effects of syn-depositional and postdepositional processes on the rare-earth element distribution in Precambrian iron-formations. European Journal of Mineralogy, 5(2), 257-268. https://doi.org/10.1127/ejm/5/2/0257

Bau, M. (1999). Scavenging of dissolved yttrium and rare earths by precipitating iron oxyhydroxide: experimental evidence for Ce oxidation, Y-Ho fractionation, and lanthanide tetrad effect. Geochimica et Cosmochimica Acta, 63(1), 67-77. https://doi.org/10.1016/ S0016-7037(99)00014-9

Bau, M., Dulski, P. (1996). Distribution of yttrium and rare-earth elements in the Penge and Kuruman ironformations, Transvaal Supergroup, South Africa. Precambriam Research, 79(1-2), 37-55. https://doi. org/10.1016/0301-9268(95)00087-9

Bau, M., Möller, P., Dulski, P. (1997). Yttrium and lanthanides in eastern Mediterranean seawater and their fractionation during redox-cycling. Marine Chemistry, 56(1-2), 123-131. https://doi.org/10.1016/S0304-4203(96)00091-6

Bolhar, R., Kamber, B. S., Moorbath, S., Fedo, C. M., Withehouse, M. J. (2004). Characterisation of early Archaean chemical sediments by trace element signatures. Earth and Planetary Science Letter, 222(1), 43-60. https://doi. org/10.1016/j.epsl.2004.02.016

Bolhar, R., Van Kranendonk, M. J. (2007). A nonmarine depositional setting for the northern Fortescue Group, Pilbara Craton, inferred from trace element geochemistry of stromatolitic carbonates. Precambrian Research, 155(3-4), 229-250. https://doi.org/10.1016/j. precamres.2007.02.002

Cook, P. J., Shergold, J. H. (1984). Phosphorus, phosphorites and skeletal evolution at the Precambrian-Cambrian boundary. Nature, 308, 231-236. https://doi.org/10.1038/308231a0

Corkeron, M., Webb, G. E., Moulds, J., Grey, K. (2012). Discriminating stromatolite formation modes using rare earth element geochemistry: trapping and binding versus in situ precipitation of stromatolites from the Neoproterozoic Bitter Springs Formation, Northern Territory, Australia. Precambrian Research, 212-213, 194-206. https://doi. org/10.1016/j.precamres.2012.04.019
De Baar, H. J. W., Bacon, M. P., Brewer, P. G. (1983). Rareearth distributions with a positive Ce anomaly in the Western North Atlantic Ocean. Nature, 301, 324-327. https://doi. org/10.1038/301324a0

De Baar, H. J. W., Bacon, M. P., Brewer, P. G., Bruland, K. W. (1985). Rare earth elements in the Pacific and Atlantic Oceans. Geochimica et Cosmochimica Acta, 49(9), 19431959. https://doi.org/10.1016/0016-7037(85)90089-4

Deb, M., Thorpe, R. I. (2004). Geochronologial constraints in the Precambrian geology of Rajasthan and their metallogenic implications. In: M. Deb, W. D. Goodfellow (eds.). Sedimenthosted lead-zinc sulphide deposits (p. 246-263). New Delhi: Narosa Publishing House.

Del Lama, E. A., Candia, M. A. F., Szabó, G. A. J. (2001). Petrography and Metamorphism of the Metasedimentary Country-Rocks of the Jacurici Valley Chromitite-Hosting Mafic-Ultramafic Complexes, Bahia, Northeastern Brazil. Geologia USP. Série Cientifica, 1, 1-15. https://doi. org/10.5327/S1519-874X2001000100002

Elderfield, H., Hawkesworth, C. H., Greaves, M. J., Calvert, S. E. (1981). Rare earth element geochemistry of oceanic ferromanganese nodules and associated sediments. Geochimica et Cosmochimica Acta, 45(4), 513-528. https:// doi.org/10.1016/0016-7037(81)90184-8

Fonseca, A. C. (2013). Geoquímica dos Elementos Terras Raras (ETR). Disponível em: http://www.geobrasil.net/ geoinfo/docs\%5Cgeoquimica.pdf. Acesso em: 20 jan. 2019.

Gaertner, C., Broecker, M., Strauss, H., Farber, K. (2011). Strontium-, carbon- and oxygen-isotope compositions of marbles from the Cycladic blueschist belt. Greece Geology, 148, 511-528. https://doi.org/10.1017/ S001675681100001X

Gama, M. (2014). Caracterização petrográfica e litogeoquímica das rochas metacarbonáticas e calcissilicáticas do Vale do Rio Jacurici, Bahia. Trabalho de Conclusão de Curso. Bahia: Instituto de Geociências - UFBA.

Grauch, R. I. (1989). Rare-earth elements in metamorphic rocks. In: B. R. Lipin, G. A. McKay (eds.). Geochemistry and Mineralogy of Rare Earth Elements. Washington, D.C.: The Mineralogical Society of America. https://doi. org/10.1515/9781501509032-009

Jardim de Sá, E. F. (1983). Geologia da Região do Vale do Jacurici. Relatório Técnico de Consultoria. SME/COM. 
Johannesson, K. H., Hawkins Jr., D. L., Cortés, A. (2006). Do Archean chemical sediments record ancient seawater rare earth element patterns? Geochimica et Cosmochimica Acta, 70(4), 871-890. https://doi.org/10.1016/j.gca.2005.10.013

Kazakov, A. V. (1937). The phosphorite facies end the genesis of Phosphonates. In: Geol. Investigations of Agricultural Ores. Trans. ScL Jnst. Fertilizers and Insecto-Fungicides, 142, 95-113.

Knoll, A. H., Kaufman, A. J., Semikhatov, M. A. (1995). The carbon isotopic composition of Proterozoic carbonates: Riphean successions from Northwestern Siberia (Anabar Massif Turukhansk uplift). American Journal of Science, 295(7), 823-850. https://doi.org/10.2475/ajs.295.7.823

Kosin, M. D., Melo, C. M., Souza, J. D., Oliveira, E. P., Carvalho, C. M. M. L. (2003). Geologia do segmento norte do Orógeno Itabuna-Salvador-Curaçá e guia de excursão. Revista Brasileira de Geociências, 33(1 Supl.), 15-26. https:// doi.org/10.25249/0375-7536.200333S11526

Lawrence, M. G., Kamber, B. S. (2006). The behaviour of the rare earth elements during estuarine mixing-revisited. Marine Chemistry, 100(1-2), 147-161. https://doi.org/10.1016/j. marchem.2005.11.007

Lee, J. H., Byrne, R. H. (1993). Complexation of trivalent rare earth elements $(\mathrm{Ce}, \mathrm{Eu}, \mathrm{Gd}, \mathrm{Tb}, \mathrm{Yb})$ by carbonate ions. Geochimica et Cosmochimica Acta, 57(2), 295-302. https:// doi.org/10.1016/0016-7037(93)90432-V

Maheshwari, A., Sial, A. N., Gaucher, C., Bossi, J., Bekker, A., Ferreira, V. P., Romano, A. W. (2010). Global nature of the Paleoproterozoic Lomagundi carbon isotope excursion: a review of occurrences in Brazil, India and Uruguay. Precambrian Research, 182(4), 274-299. https://doi. org/10.1016/j.precamres.2010.06.017

Marinho, M. M., Rocha, G. F., Deus, P. B., Viana, J. S. (1986). Geologia e potencial cromitífero do Vale do Jacurici, Bahia: XXXIV Congresso Brasileiro de Geologia, 5, 20742088. Goiânia, SBG.

Marques, J. C., Ferreira Filho, C. F. (2003). The chromite deposits of the Ipueira Medrado Sill, Bahia, Brazil. Economic Geology, 98(1), 87-108. https://doi.org/10.2113/98.1.87

McLennan, S. M. (1989). Rare earth elements in sedimentary rocks: influence of provenance and sedimentary processes. In: B. R. Lipin, G. A. McKay (Eds.). Geochemistry and Mineralogy of Rare Earth Elements. Washington, D.C.: The Mineralogical Society of America. https://doi. org/10.1515/9781501509032-010
Moller, P., Bau, M. (1993). Rare earth patterns with positive Ce anomaly in alkaline water from Lake Van, Turkey. Earth and Planetary Science Letters, 117(3-4), 671-676. https:// doi.org/10.1016/0012-821X(93)90110-U

Nelson, G. J., Pufahl, P. K., Hiatt, E. E. (2010). Paleoceanographic constraints on Precambrian phosphorite accumulation, Baraga Group, Michigan, USA. Sedimentary Geology, 226(1-4), 9-21. https://doi.org/10.1016/j. sedgeo.2010.02.001

Nozaki, Y., Zhang, J., Amakawa, H. (1997). The fractionation between $\mathrm{Y}$ and Ho in the marine environment. Earth and Planetary Science Letters, 148(1-2), 329-340. https://doi. org/10.1016/S0012-821X(97)00034-4

Oliveira, E. P., Grisólia, M. F., Moreto, C., Donatti Filho, J. P., McNaughton, N., Vale, I. Z., (2010). Descoberta de um Complexo de Fore-arc Paleoproterozoico no Greenstone Belt do Rio Itapicuru, Bahia, e Implicações Geodinâmicas. XXXXV Congresso Brasileiro de Geologia. Belém: SBG.

Oliveira, E. P., Windley, B. F., McNaughton, N. J., Pimentel, M., Fletcher, I. R. (2004). Contrasting copper and chromium metallogenic evolution of terranes in the Paleoproterozoic Itabuna-Salvador-Curaçá orogen, São Francisco craton, Brazil: new zircon (SHRIMP) and Sm-Nd (model) ages and their significance for orogen-parallel escape tectonics. Precrambian Research, 128(1-2), 143-165. https://doi. org/10.1016/j.precamres.2003.09.018

Papineau, D. (2010). Global biogeochemical changes at both ends of the Proterozoic: insights from phosphorites. Astrobiology, 10(2), 165-181. https://doi.org/10.1089/ ast.2009.0360

Piper, D. Z. (1974). Rare-Earth Elements in the Sedi Cycle: A Summary. Chemical Geology, 14(4), 285-304. https://doi. org/10.1016/0009-2541(74)90066-7

Planavsky, N., Bekker, A., Rouxel, O. J., Kamber, B., Hofmann, A., Knudsen, A., Lyons, T. W. (2010). Rare earth element and yttrium compositions of Archean and Paleoproterozoic Fe formations revisited: new perspectives on the significance and mechanisms of deposition. Geochimica et Cosmochimica Acta, 74(22), 6387-6405. https://doi. org/10.1016/j.gca.2010.07.021

Pufahl, P. K., Hiatt, E. E. (2012). Oxygenation of the Earth's atmosphere-ocean system: a review of physical and chemical sedimentologic responses. Marine and Petroleum Geology, 32(1), 1-20. https://doi.org/10.1016/j.marpetgeo.2011.12.002 
Ribeiro, T. S. (2016). Caracterização geológica das rochas calcissilicáticas e metacarbonáticas do complexo Tanque Novo-Ipirá na folha Pintadas - BA: potencial metalogenético para fosfato. Dissertação (Mestrado). Salvador: Instituto de Geociências - UFBA.

Ribeiro, T. S. (2017). Complexo Tanque Novo-Ipirá: Geologia e potencialidade para fosfato na folha Pintadas, Bahia. CBPM. Série Arquivos Abertos, 42.

Sanches, A. L. (1997). O Fosforito proterozoico da região de Irecê (Bahia). Dissertação (Mestrado). Salvador: Instituto de Geociências - UFBA.

Sarangi, S., Gopalan, K., Roy, A. B., Sreenivas, B., Das Sharma, $\mathrm{S}$. (2006). $\mathrm{Pb}-\mathrm{Pb}$ age of the carbonates of Jhamarkotra Formation constraining the age of the Aravalli Supergroup, Rajasthan. Journal of the Geological Society of India, 67(4), 442-446.

Shields, G., Stille, P., Brasier, M. D. (2000). Isotopic records across two phosphorite giant episodes compared: the Precambrian-Cambrian and the late Cretaceous-Recent. In: C. R. Glenn, L. Prevot, J. Lucas (eds.). Marine authigenesis: from global to microbial (p. 103-116). Tulsa: SEPM. https:// doi.org/10.2110/pec.00.66.0103
Silveira, C. J. S., Frantz, J. C., Marques, J. C., Queiroz, W. J. A., Roos, S., Peixoto, V. M. (2015). Geocronologia $\mathrm{U}-\mathrm{Pb}$ em zircão de rochas intrusivas e de embasamento na região do Vale do Jacurici, Cráton do São Francisco, Bahia. Brazilian Journal of Geology, 45(3), 453-474. https://doi. org/10.1590/2317-488920150030233

Swart, P. K. (2015). The geochemistry of carbonate diagenesis: the past, present and future. Sedimentology, 62(5), 12331304. https://doi.org/10.1111/sed.12205

Taylor, S. R., McLennan, S. M. (1985). The continental crust: its composition and evolution. Oxford: Blackwell Scientific Publications.

Towe, K. M. (1991). Aerobic carbon cycling and cerium oxidation: significance for Archean oxygen levels and banded iron-formation deposition. Global and Planetary Change, 97(12), 113-123. https://doi.org/10.1016/0031-0182(91)90187-V

Veizer, J., Plumb, K. A., Clayton, R. N., Hinton, R. W., Grotzinger, J. P. (1992). Geochemistry of Precambrian carbonates: V. Late Paleoproterozoic seawater. Geochimica et Cosmochimica Acta, 56(6), 2487-2501. https://doi. org/10.1016/0016-7037(92)90204-V 